Elsevier Editorial System(tm) for Journal of Hydrology Manuscript Draft

Manuscript Number: HYDROL7104R2

Title: Multi-scale soil moisture measurements at the Gourma meso-scale site in Mali

Article Type: Special Issue; Lebel AMMA

Keywords: Soil Moisture; ground measurements; Sahel; AMMA

Corresponding Author: Dr Patricia de Rosnay,

Corresponding Author's Institution: ECMWF and CNRS/CESBIO

First Author: Patricia de Rosnay

Order of Authors: Patricia de Rosnay; Claire Gruhier; Franck Timouk; Eric Mougin; Pierre Hiernaux; Laurent Kergoat; Valérie Le Dantec 


\section{detailed response to reviewer \#2}

Paper HYDROL7104 entitled "Multi-scale soil moisture measurements at the Gourma meso-scale site in Mali”, by P. de Rosnay, C. Gruhier, F. Timouk, F. Baup, E. Mougin, P.

Hiernaux, L. Kergoat, V. Le Dantec.

The authors thank very much this reviewer for his very helpful comments and discussion on this paper. Here is addressed the minor comment of the second revision.

" The authors have significantly improved the manuscript and well responded to the comments by the reviewers. The only remark I have is how the wording related to correlation from line 367 and onwards. $R 2$ is the explained variance of a regression and is as a rule expressed in percentage while $R$ is the (multiple) correlation of the regression. The latter is as a rule not expressed in percentage. It is unclear in the text what "correlation value" means - R2 or R? I advise publication after this minor revision."

Yes we agree. The term correlation is used everywhere in the text. $\mathrm{R}$ indicates the correlation (while $R^{2}$ would be indicated as the determination coefficient). In this study, the figures given are all correlation $\mathrm{R}$ (not $R^{2}$ ). This inconsistency has been removed everywhere in the text, in Table 4 and in Figures 6 and 7, where the term $\mathrm{R}$ is now used. Accordingly, percentage are not used anymore. 


\title{
Multi-scale soil moisture measurements at the Gourma meso-scale site in Mali
}

\author{
P. de Rosnay ${ }^{\mathrm{a}, \mathrm{b}, *}$, C. Gruhier ${ }^{\mathrm{c}}$ F. Timouk $^{\mathrm{d}}$ F. Baup, ${ }^{\mathrm{e}}$

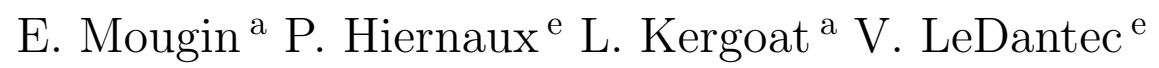 \\ ${ }^{\mathrm{a}}$ CNRS/CESBIO, Toulouse, France \\ ${ }^{\mathrm{b}} E C M W F$, Reading, UK \\ ${ }^{\mathrm{c}}$ CNRS/CNES/CESBIO, Toulouse, France \\ d IRD/CESBIO, Toulouse, France \\ ${ }^{\mathrm{e}} U P S / C E S B I O$, Toulouse, France
}

\begin{abstract}
This paper presents the ground soil moisture measurements performed over the socalled Gourma meso-scale site in Mali, Sahel, in the context of the African Monsoon Multidisciplinary Analysis (AMMA) project. The Gourma meso-scale soil moisture network is part of a complete land surface processes observing and modelling strategy and is associated to vegetation and meteorological field measurements as well as soil moisture remote sensing. It is spanning $2^{\circ}$ in latitude between $15^{\circ} \mathrm{N}$ and $17^{\circ} \mathrm{N}$. In 2007, it includes 10 soil moisture stations, of which 3 stations also have meteorological and flux measurements. A relevant spatial sampling strategy is proposed to characterise soil moisture at different scales including local, kilometer, super-site and meso-scales. In addition to the local stations network, transect measurements were performed on different coarse textured (sand to sandy-loam) sites, using portable impedance probes. They indicate mean value and standard deviation (STD) of the
\end{abstract}


surface soil moisture (SSM) at the kilometer scale. This paper presents the data set and illustrates soil moisture spatial and temporal features over the Sahelian Gourma meso-scale site for 2005-2006. Up-scaling relation of SSM is investigated from (i) local to kilometer scale and (ii) from local to the super site scale. It is shown to be stable in space and time (2005-2006) for different coarse textured sites. For the Agoufou local site, the up-scaling relation captures SSM dynamics at the kilometer scale with a $0.9 \%$ accuracy in volumetric soil moisture. At the multi-site scale, an unique up-scaling relation is shown to be able to represent kilometer SSM for the coarse textured soils of the meso-scale site with an accuracy of $2.2 \%$ (volumetric). Spatial stability of the ground soil moisture stations network is also addressed by the Mean Relative Difference (MRD) approach for the Agoufou super site where 5 soil moisture stations are available (about $25 \mathrm{~km} \times 25 \mathrm{~km}$ ). This allows the identification of the most representative ground soil moisture station which is shown to be an accurate indicator with low variance and bias of the soil moisture dynamics at the scale of the super site. Intensive local measurements, together with a robust upscaling relation make the Gourma soil moisture network suitable for a large range of applications including remote sensing and land surface modelling at different spatial scales.

Key words: Soil Moisture, ground measurements, up-scaling, Sahel, AMMA

\section{$1 \quad 1 \quad$ Introduction}

2 West Africa, and more specifically the Sahel, is pointed out by Koster et al. (2004)

3 to be one of the regions of the world with the strongest feedback mechanism between

4 soil moisture and precipitation. This hot spot "indicates where the routine monitor-

* Corresponding author: Tel: +44 118949 9625, Fax: +44 1189869450

Email address: Patricia.Rosnay@ecmwf .int (P. de Rosnay). 
5 ing of soil moisture, with both ground-based and space-based systems, will yield the

6 greatest return in boreal summer seasonal forecasting." One of the key objectives of

7 AMMA (African Monsoon Multidisciplinary Analysis) project, is to improve our un-

8 derstanding and our modelling capabilities of the effect of land surface processes on

monsoon intensity, variability and predictability (Redelsperger et al. 2006). AMMA

10 is supported by a very strong observational program. Three meso-scale sites are

1 instrumented in Mali, Niger and Bénin, providing information along the North-

2 South gradient between Sahelian and Soudanian regions (Redelsperger et al. 2006).

13 The instrumental deployment in the Gourma region (the sahelian site of Mali) fo-

14 cuses on quantification of water, $\mathrm{CO} 2$ and energy fluxes between the surface and

the atmosphere (Mougin et al., this issue). Among the surface processes under

consideration, emphasis is put on evapotranspiration which is the most important

17 process coupling the physical, biological and hydrological processes at the conti-

nental scale. Soil moisture is a crucial variable that affects many processes includ-

19 ing land-surface-atmosphere interactions (Taylor et al. 2007; Taylor and Ellis 2006;

Monteny et al. 1997; Nicholson et al. 1997), land surface fluxes (Timouk et al. this issue; Lloyd et al. 1997), vegetation phenology (Seghieri et al. this issue), and soil respiration (Le Dantec et al. 2006). The diversity of processes and the corresponding large range of spatial and temporal scales involved in the monsoon dynamics require accurate estimate of soil moisture dynamics at local scale, meso-scale and regional scale. Ground measurements provide vertical soil moisture profiles with a high accuracy but they are limited to the local scale. In contrast, remote sensing ap-

but they are limited to the very first top centimetres of the soil (Kerr 2007). Soil moisture estimation from microwave remote sensing was investigated during the $\mathrm{Hy}-$ drological and Atmospheric Pilot Experiment in the Sahel (HAPEX-SAHEL), using both passive microwave radiometry from airborne measurements (Schmugge 1998; Chanzy et al. 1997; Calvet et al. 1996) and active microwave remote sensing with 
ERS satellite data (Magagi and Kerr 1997). These studies were based on local soil moisture ground measurements acquired for a few month during the 1992 summer campaign. Extensive field measurement campaigns have been conducted in other regions of the Earth to characterise the soil moisture variability, as for example in the U.S. Midwest, South Central Georgia and Southern Great Plains (SGP) (De Lannoy et al. 2007; Bosch et al. 2006; Famiglietti et al. 1999), and in Australia (Rüdiger et al. 2007). Using airborne based remote sensing information, Kim and Barros (2002) examined the statistical structure of soil moisture $(40 \times 250 \mathrm{~km})$ obtained during the SGP 1997 hydrology experiment. In Sahel, where field instrumentation and extensive field campaigns are more difficult, extensive soil moisture measurements were not available until now. In the framework of AMMA the Gourma meso-scale site has been instrumented for soil moisture measurements. It is described in this paper.

For the purpose of satellite validation it is of crucial importance to address up-scaling issues of ground soil moisture measurements. Baup et al. (2007) used ground soil moisture measurements over the Agoufou local site, in Mali, for the purpose of ENVISAT/ASAR soil moisture inversion. To this end they used surface soil moisture measurements from one local station, up-scaled to the $1 \mathrm{~km}$ remotely sensed pixel for 2005. In the present paper, surface soil moisture up-scaling of ground measurements is investigated at the single site scale and extended to (i) the multi-site spatial scale, within the Gourma meso-scale windows, and (ii) the inter-annual temporal scale. A complementary approach, suitable for larger scale applications, consists of deriving spatially representative soil moisture estimates from ground observation networks. The method, first proposed by Vachaud et al. (1985), is based on the Mean Relative Difference (MRD) and deviation between stations of the same network. It was applied by Cosh et al.(2004) to the Soil Moisture EXperiment (SMEX) 2002 (Jackson et al. 2003) for the validation of the Advanced Microwave Scanning Radiometer on Earth Observing System (AMSR-E) soil moisture. De Lannoy et al. 
(2007) used the MRD approach combined with cumulative distribution function matching to estimate the spatial mean soil moisture. Based on the MRD, Gruhier et al. (2008) used the Gourma meso-scale soil moisture measurements to validate the soil moisture products obtained for 2005 from AMSR-E.

Ground soil moisture measurements are also highly relevant to validate Land Surface Models (LSMs). As for satellite validation, up-scaling is crucial to characterise soil moisture at the scale of the LSM. In turn, land surface models allow for the extension of local scale measurements to larger spatial scales. This is being addressed over West Africa through the AMMA Land Surface Model Intercomparison Project (ALMIP, Boone et al. 2008).

The main purpose of this paper is to describe the Gourma meso-scale soil moisture network and to presents soil moisture measurements for 2005-2006. Based on local and transect measurements and using the Mean Relative Difference method, this paper also presents some features of the soil moisture characteristics and investigates the potential of the Gourma soil moisture measurements to address surface soil moisture up-scaling. Next section describes the Gourma meso-scale soil moisture network. Section 3 presents the soil moisture dynamics for different stations along the $15^{\circ} \mathrm{N}$ to $17^{\circ} \mathrm{N}$ climatic gradient for 2005 and 2006. Section 4 focuses on surface soil moisture up-scaling. Representativity of ground soil moisture station is addressed in section 5 for the Agoufou super site, where the Mean Relative Difference approach is applied to the Gourma soil moisture network. Section 6 concludes. 


\section{Experimental design and ground soil moisture measurements}

\subsection{The Mali site}

The AMMA project aims at providing a better understanding of the African monsoon processes. AMMA relies on an extensive field campaign experiment for which three meso-scale sites are instrumented in Bénin, Niger and Mali (Redelsperger et al. 2006).

Instrumental deployment over the Mali site includes three monitoring scales described hereafter (Mougin et. al, this issue).

- The Gourma meso-scale site $\left(30,000 \mathrm{~km}^{2}, 14.5^{\circ} \mathrm{N}-17.5^{\circ} \mathrm{N} ; 1^{\circ} \mathrm{W}-2^{\circ} \mathrm{W}\right)$ is shown in Figure 1. The location of the soil moisture stations (10 stations) is indicated on the map by white stars. Each soil moisture station also includes a rain-gauge for rainfall measurements and three stations (in Bamba, Eguérit, Agoufou) include complete weather station and flux measurements. More detail on rainfall measurements over Gourma are provided in Frappart et al. (this issue), while Lebel and Ali (this issue) investigate the rainfall regime fluctuations in Sahel. The Gourma meso-scale site is characterised by a Sahelian to saharo-sahelian climate (isohyets $500-100 \mathrm{~mm}$ ). Soil is coarse textured (sand, loamy sand, sandy loam) for $65 \%$ of the area, where vegetation is composed of a layer of natural annual herbs with scattered trees and shrubs (Hiernaux et al. this issue). $28 \%$ of the meso-scale site is characterised by flat and shallow soils and rock outcrops (loamy colluvium, schist, sandstone outcrops and hard pan). Vegetation on these rocky-loam areas consists of scattered shrubs. The remaining $7 \%$ of the area are clay plains, temporarily flooded woodlands and flooded depressions. Data on herbs and woody vegetation are collected on 43 local sites among which some are also used for validation of remote sensing products (LAI, Net Primary Productivity, soil moisture) derived form SPOT-VGT, MODIS, AMSR-E, ENVISAT/ASAR, ERS (Gruhier 
- The Agoufou super site $\left(2,250 \mathrm{~km}^{2}, 15.3^{\circ} \mathrm{N}-15.58^{\circ} \mathrm{N} ; 1.38^{\circ} \mathrm{W}-1.65^{\circ} \mathrm{W}\right)$ is shown in Figure 1 (right). At this scale, ground measurements focus on land surface fluxes measurements as well as on spatial heterogeneities of fluxes and vegetation characteristics.

- The Agoufou local intensive site $\left(1 \mathrm{~km}^{2}, 15.3^{\circ} \mathrm{N} ; 1.3^{\circ} \mathrm{W}\right)$ is indicated on Figure 1. Annual mean precipitation is $370 \mathrm{~mm}$ (1920-2003). The site has measurements of vegetation, soil moisture, meteorology and land surface fluxes (energy, water, CO2). The data collected on this site are used to parameterise, test and validate LSMs. The Agoufou local site is also a main validation site for remote sensing products.

\subsection{Ground soil moisture measurements}

The colours in Figure 1, obtained from a Landsat image, indicate the surface types on which the stations are deployed, with green for gently undulating coarse textured dune systems, dark green for clay soil types and brown-pink for flat rockyloam plains. Table 1 provides detailed information concerning soil moisture stations (number, name, soil type, location, sensors types and depth, date of installation). The same installation protocol is used for all the soil moisture stations, where Time Domain Reflectometry sensors are used (Campbell CS616), except for the Kelma station. For the later, Delta-T Theta Probe sensors are used since they are equipped with short rods which is more suitable for clay soils (a mention of the manufacturers is for information only and implies no endorsement on the part of the authors). The Gourma soil moisture stations all include a first measurement at $5 \mathrm{~cm}$ depth, except in Eguérit (rocky) where the first measurement is at $10 \mathrm{~cm}$ depth. Soil moisture profiles are measured down to $50 \mathrm{~cm}$ depth for Eguérit, and down to $4 \mathrm{~m}$ for Agoufou 
at the bottom of a hillslope. In order to capture the fast soil moisture dynamics, the vertical resolution of automatic soil moisture measurements in the soil is very fine at the surface, and measurements are acquired at 15 minutes time intervals. For remote sensing and land surface modelling purpose, both soil moisture and soil temperature profiles are monitored. For each station and each sensor depth, calibration was performed, based on local soil density and gravimetric soil moisture measurements. Gravimetric measurements were performed at different stages of the rainy season to ensure calibration robustness in various soil moisture conditions. Soil moisture values provided in this paper are expressed in terms of volumetric units.

Soil texture measurements were performed for the first meter of soil, in the Agoufou local intensive site at the top and bottom of a hillslope (Table 2). Soil texture of the top $10 \mathrm{~cm}$ of soil is slightly different between the top and bottom of the hillslope, with silt and clay content higher at the bottom than at the top of the hillslope. However the soil is very coarse textured, with more than $74 \%$ and $94 \%$ of sand particles at surface for the bottom and top of the hillslope respectively.

The Gourma soil moisture network documents soil moisture dynamics along the North-South climatic gradient, as well as at the dune scale, with three stations located on the Agoufou local site at different levels of a typical hillslope (top, middle and bottom). Eight stations are located on coarse textured soils (sandy to sandyloam) which represents $65 \%$ of the meso-scale site area. One station, in Kelma (site 21 ) is implemented on a clay soil, covered by acacia forest, representing $7 \%$ of the meso-scale area, and one station is located in Eguérit, on a rocky surface that represents $28 \%$ of the area.

In addition to the local stations network, transect measurements have been manually performed every year since 2004 during the rainy season. They consist in monitoring surface soil moisture $(0-5 \mathrm{~cm})$ by the means of a portable impedance probe (Theta probe) every $10 \mathrm{~m}$ along a $1 \mathrm{~km}$ straight transect. The location of each 
point measurement along the transect is chosen to be different (separated by a few centimetres) from one transect date to another. This ensures avoiding soil disturbances that would affect the soil moisture measurements. This method allows estimating, for each transect measurement, both the mean value and standard deviation of the surface soil moisture along the $1 \mathrm{~km}$ transect. For practical reasons it is not possible to perform transect measurements on rocky surfaces (too hard to use the probe), nor in flooded plains (under water). Thus transect measurements have been performed on coarse textured soils, which represent the dominant soil texture type at meso-scale. Intensive transect measurements campaigns were performed on the Agoufou local site where soil moisture is the most intensively documented. For this site the $1 \mathrm{~km}$ transect is the same as that used for vegetation measurements (Hiernaux et al. this issue). It is located on the Agoufou site with the starting and closest point located about $100 \mathrm{~m}$ from the Agoufou bottom of the hillslope station (P1) and about 300m from the top of hillslope (P3) and middle of hillslope (P2) stations. In 2005 and 2006, transect measurements were also extended to the other coarse textured sites of Bangui Mallam, Ekia and Bamba. For these 3 sites, the $1 \mathrm{~km}$ transects start exactly from the soil moisture stations. The $1 \mathrm{~km}$ transects aim to provide information on mean surface soil moisture at the kilometer scale. These measurements are not combined with topography measurements. In 2006 an additional transect was defined on the Agoufou local intensive site for the purpose of hydrological applications and vegetation monitoring in relation to soil moisture along a topographic profile. SSM measurements performed along the hydrological transect are combined with elevation measurements. In contrast to the $1 \mathrm{~km}$ transects, this hydrological transect is not straight. It is $1255 \mathrm{~m}$ long and cuts across 7 catchments located partly within the Agoufou intensive site. It starts from the top of hillslope (P3) station, passes on the bottom of hillslope station (P1) and it is at a distance of about $100 \mathrm{~m}$ from the middle of hillslope station (P2). Table 3 indicates the number of transect measurements performed on each site for these two years. 
Remote sites, more difficult to access, are less documented, as in Bamba where only 1 transect measurement was performed.

[Table 1 about here.]

[Table 2 about here.]

[Table 3 about here.]

[Fig. 1 about here.]

\section{Soil Moisture Dynamics over the Gourma meso-scale site}

\subsection{Temporal dynamics}

Inter-annual variability between 2005 and 2006 is shown in Figure 2 for the surface (5cm depth) soil moisture monitored for eight stations located along the north-south gradient and for different soil types. The horizontal axis indicates the Day of Year (DoY). Note that the vertical axis is identical for each station except Kelma (P9, bottom right). Kinia (P11) and Agoufou middle (P2) are not presented since the data set is not complete for the considered period. In the In Zaket station, the 2005 data set is limited to DoY 198-228, which provides one month of data between the station installation in July and its theft in August. The 2006 data set is complete after the station was reinstalled. Data are missing for Eguérit in early 2006 for technical reasons. So inter-annual variability in monsoon onset is not visible for these two last stations.

The top panel shows SSM of the most northern stations in Bamba and In Zaket. They both present similar features in their surface soil moisture dynamics which is relatively slow and low amplitude. The second panel shows the surface soil mois- 
ture dynamics for Ekia and Bangui Mallam and the third panel presents surface soil moisture for two stations located in the Agoufou super site at the top and bottom of the hillslope. Surface soil moisture is characterised by higher values and a larger temporal variability on these sites than on the northern sites. The bottom panel shows the surface soil moisture evolution for the two non-sandy sites of the Gourma soil moisture network, located in Eguérit (rocky) and in Kelma (clay). They both show a lower temporal variability in surface soil moisture. The Kelma site is characterised by much higher soil moisture values, due to the clay soil texture in this area. In addition, this site is flooded during the rainy season as indicated by the maximum soil moisture values maintained at saturation for more than one month during the monsoon season. For the top three panels, which present surface soil moisture monitored on coarse textured sites, differences between the sites are mainly governed by the strong North-South climatic gradient and by the precipitation variability. In contrast, for the bottom panel, the distances between the sites is less (all sites are within the super site) and the precipitation variability between the sites is lower. Accordingly, differences in soil moisture dynamics are mainly governed for these sites by differences in surface properties (soil texture and vegetation cover) and subsequent land surface processes (partitioning between evapotranspiration and runoff).

For coarse textured soils the infiltration rate is very high according to the large amount of sand particles (higher than 74\%). Surface ponding occurs rarely on these soils and it is located in very specific and limited areas (a few square meters) for very short periods (a few hours after rain). None of the soil moisture stations installed on coarse textured soils are affected by ponding. Despite temporal dynamics and absolute values of soil moisture being different between stations depending on both surface properties and location along the climatic transect, all the stations capture the later monsoon onset in 2006 than in 2005 that was described by Janicot et al. (2008). 


\subsection{Vertical dynamics}

Figure 3 (top) depicts the temporal evolution of soil moisture at different depths at the Bangui Mallam station during the 2006 summer. It clearly shows that soil moisture dynamics is very fast at the surface, with rapid soil moisture response to precipitation occurrence, and fast soil drying afterwards. Soil moisture dynamics is getting slower with increasing depth, and at $120 \mathrm{~cm}, 180 \mathrm{~cm}$ and $250 \mathrm{~cm}$ depth, soil moisture shows variability mainly at the seasonal time scale.

A major rainfall event (61.5mm at this station) occurred in the early morning of the DoY 210. It was associated with a large convective system that gave precipitation from Kelma to Ekia (Figure 1), as can be seen on Figure 2 with the surface soil moisture increasing on DoY 210 in 2006 for the 6 stations concerned. This event is chosen here to illustrate the vertical soil moisture dynamics at the Bangui Mallam site which is representative of vertical dynamics of coarse textured sites of the Gourma region.

Figure 3 (middle) shows the vertical structure of soil moisture evolution of the Bangui Mallam station at four different dates around this precipitation event, between July 28 (DoY 209) and August 2 (DoY 214) 2006. Figure 3 (bottom) shows the water budget as estimated from ground observations of soil moisture and precipitation for this period for the Bangui Mallam site. In particular it indicates the accumulated precipitation since DoY 209, and the variation in total soil water content (W) for the $0-1 \mathrm{~m}$ soil layer and for the $1-2 \mathrm{~m}$ soil layer (dW $0-1 \mathrm{~m}$ and $\mathrm{dW} 1-2 \mathrm{~m}$ respectively). Vertically integrated soil water content is computed for each time step by the means of a linear vertical interpolation and integration of volumetric soil moisture profiles. Accordingly it must be taken with caution due to uncertainties associated to the vertical profiles. This is particularly the case for the second meter of soil where the 
vertical sampling of soil sensors is more sparse (Table 1). After a rainfall event, the presence of a wetting front, associated to a discontinuity in the soil moisture profile, is also expected to affect the accuracy of the vertical interpolation. Despite of these uncertainties, when considering its temporal evolution, the vertically integrated water content provides an estimate of the time evolution of the soil water budget.

Soil moisture profiles shown in Figure 3 (middle) indicate very dry conditions (volumetric soil moisture below 2\% ) on DoY 209 at all soil depths at the Bangui Mallam station. The strong precipitation event that occurred on DoY 210 led to a fast response of soil moisture in the first half meter of soil, with an increase to $12.5 \%$ (volumetric) at $10 \mathrm{~cm}$ depth. However the wetting front didn't reach yet the $80 \mathrm{~cm}$ deep soil moisture sensor for which the volumetric soil moisture was steady bellow $2 \%$. The vertical profile depicted for DoY 211 shows that 1.5 days after the rain occurred, the wetting front got deeper, down to $80 \mathrm{~cm}$, while the first $30 \mathrm{~cm}$ of soil already started to dry out. A few days later (DoY 214) while 2 rainfall events occurred (21.5mm each) in the morning and evening of the DoY 212, the vertical profile of soil moisture shows that the wetting front reached $120 \mathrm{~cm}$ depth. Figure 3 (bottom) shows that the cumulated rainfall between DoY 209 and 214 is $104 \mathrm{~mm}$. The total soil water increase $(\mathrm{dW} 0-1 \mathrm{~m}+\mathrm{dW} 1-2 \mathrm{~m})$ for this period is $85.3 \mathrm{~mm}$. The lower value of total soil water increase compared to accumulated precipitation, is explained by several processes, including direct soil evaporation, water uptake for plant transpiration and surface runoff. It is interesting to note that, for each of the three rainfall events, the $0-1 \mathrm{~m}$ soil water content decreased rapidly as soon as the rain stopped. It is due to direct soil evaporation and strong rates of plant transpiration. In addition, the downward propagation of the wetting front, when it reached the $1-2 \mathrm{~m}$ soil layer, strongly contributed to the $0-1 \mathrm{~m}$ layer drying after DoY 213 (2.75 day after the first rainfall event). At the same time, dW1-2m started to strongly increase accordingly on DoY 213, due to deep soil infiltration from the first meter to the second meter of soil. 


\section{Surface soil moisture up-scaling}

Results of transect measurements are presented in this section. The local to kilometer up-scaling relation is investigated at the single-site scale, considering annual and inter-annual temporal scales, as well as at the multi-site scale. As described in section 2 and Table 3, transect measurements were performed in 2005 and 2006 during intensive field campaign measurements conducted during the monsoon season.

\subsection{Bangui Mallam site}

Figure 4 illustrates the surface soil moisture variability along the Bangui Mallam $1 \mathrm{~km}$ transect, for which measurements were performed at different dates between 11 and 16 August 2006. A strong precipitation event occurred on August 9 (DoY 221), 2 days before the first transect measurement, followed by a long drying period. This figure illustrates the strong spatial variability along the transect. However, values of standard deviation (STD) indicated on the figure for the three dates, also show that surface soil moisture spatial variability decreases when soil is drying. The relationship between the soil moisture mean value and its spatial variability is investigated further in section 4.3 at the multi-site scale. Figure 4 also shows the very fast temporal dynamics associated with the soil drying after a precipitation event. In five days, volumetric surface soil moisture drops from $10.8 \%$ to $1.0 \%$. This fast drying of the soil surface is due to fast infiltration rates of coarse textured soils and large evaporation rates. 
Based on transect measurements and local station measurements at Bangui Mallam acquired at the same time, a relationship is established between the averaged $1 \mathrm{~km}$ transect surface soil moisture $\left(S S M_{\text {tra1km }}\right)$ and the local station surface soil moisture $\left(S S M_{\text {staloc }}\right)$ for the Bangui Mallam site in 2006:

$$
S S M_{\text {tra } 1 \mathrm{~km}}=-2.2365+1.5458 \times S S M_{\text {staloc }}
$$

where both $S S M_{\text {tra1km }}$ and $S S M_{\text {staloc }}$ are in \% (volumetric). The slope larger than 1 (1.5458) indicates slightly stronger surface soil moisture changes on the transect compared to the local station. This is explained by the difference of sensing depth between the local station and transect measurements. The top few centimetres of the soil are characterised by very strong soil moisture (and soil temperature) gradients. The very surface soil moisture, which is more directly exposed to the atmosphere, depicts slightly larger variations than at $5 \mathrm{~cm}$ depth, where the variations are already slightly attenuated. Thus the time evolution of the surface soil moisture is sensitive to the depth of measurement. This issue has important implications for remote sensing applications which measure about the top $1 \mathrm{~cm}, 2 \mathrm{~cm}$ and $5 \mathrm{~cm}$ soil moisture at X-band, C-band and L-band respectively, as indicated by Le Morvan et al. 2008 and Jackson et al., 1997. In our study the first sensor of the station is horizontally placed at $5 \mathrm{~cm}$ depth, whereas the transect measurements measure the averaged value between 0 and $5 \mathrm{~cm}$ deep. Shallower measurements lead to slightly larger soil moisture variations along the transects than at the station. This is expressed by a slope larger than one between transect and station measurements. This relationship applied to the station surface soil moisture measurements, allows extrapolating to the kilometer scale, for which $S S M_{s t a 1 k m}$ will be used. Table 4 (first line) shows the statistical results of the comparison between the kilometer surface 
soil moisture obtained from extrapolated station measurements $\left(S S M_{s t a 1 \mathrm{~km}}\right)$ and from the transect measurements $\left(S S M_{t r a 1 k m}\right)$. Comparison is based on several indicators including Root Mean Square Error $(R M S E)$, correlation coefficient $(R)$, Efficiency (Nash coefficient, EFF) and BIAS. Although only seven transects are considered to determine this relation for the Bangui Mallam site in 2006, the very good agreement between the station and the transect measurements $(R=0.89$, $\left.R M S E=1.6 \%, E F F=0.8, B I A S=10^{-4}\right)$, indicates that the up-scaling relation provided in equation 1 is highly suitable to extrapolate from local station measurements at the Bangui Mallam site, to the kilometer scale. Since the station operates automatically, this approach is suitable to derive the kilometer scale surface soil moisture continuously at a fine temporal resolution (15 minute time step). These statistics are obtained when the complete transect data are used. They include 100 measurements for each transect (1 measurement every $10 \mathrm{~m})$. The sensitivity of the correlation to the spatial sampling along the transect is relatively low (not shown). For this site the correlation values stay in the range of 0.87 when measurements are taken every $200 \mathrm{~m}$ (only 5 measurements), to 0.92 when measurements are taken every $80 \mathrm{~m}$ (13 measurements). The stability of the temporal correlation for different spatial sampling distances indicates that the surface soil moisture temporal variability is rather homogeneous along the transect. This explains the robustness of the kilometer scale up-scaling relation.

\subsection{Up-scaling relation for the Agoufou site}

Measurements performed in 2005 and 2006 on the Agoufou site are used here to investigate the inter-annual stability of the up-scaling relationship between surface soil moisture at the local station scale and at the kilometer scale. As indicated in Table 3, 34 1km-transect observations were made for this period on the Agoufou site. The transects cover a wide range of soil moisture conditions. The Agoufou 
site includes 3 soil moisture stations, of which the data from two stations (top and bottom) are available for the whole 2005-2006 period (Table 1). The up-scaling relationship between local and kilometer surface soil moisture is computed and indicated below for theses two stations.

For the Agoufou top of hillslope station:

$$
S S M_{\text {tra } 1 \mathrm{~km}}=-0.68855+1.7561 \times S S M_{\text {staloc }}
$$

For the Agoufou bottom of hillslope station:

$$
S S M_{\text {tra } 1 \mathrm{~km}}=-5.272+1.1812 \times S S M_{\text {staloc }}
$$

Lower slope and intercept parameters are obtained for the bottom of hillslope station than for the top of hillslope one. As expected, this is due to generally higher values of soil moisture content at the bottom than at the top of hillslope. These two relations are applied to the data continuously monitored by the stations in order to estimate the kilometer scale surface soil moisture. Figure 5 shows the scatter-plot of the comparison of the kilometer scale surface soil moisture between station and transect. Statistical results are indicated in Table 4 for Agoufou 2005-2006. Bottom of hillslope up-scaled soil moisture shows a slightly non-linear behaviour related to a pronounced saturation effect for high values of soil moisture.

[Fig. 5 about here.]

[Table 4 about here.]

For this two-year period, best results are obtained with the top of hillslope station, for which the up-scaling relation matches the transect measurements with an accuracy better than $1 \%$ (volumetric), and a correlation coefficient of $R=0.97$. Values of efficiency are also very high for both stations with 0.94 and 0.73 for the top 
and bottom station respectively. These statistical results indicate that the up-scaling relation between local surface soil moisture and averaged surface soil moisture along the $1 \mathrm{~km}$ transect is very stable at the inter-annual scale.

Further analysis is conducted to compare surface soil moisture up-scaling performances from the three stations of the Agoufou site, which was only possible for 2006. Statistical results are shown in Table 4. The top of hillslope station (P3) is shown to be the most suitable to up-scale surface soil moisture to the kilometer scale.

\subsection{Multi-site up-scaling relation}

The spatial stability of the $1 \mathrm{~km}$ up-scaling relation is addressed here at the multisite scale. The $1 \mathrm{~km}$ transects acquired on the Agoufou site and on the other coarse textured sites are considered for this study. Since much more measurements were acquired on Agoufou, only the year 2006 is considered for this site, while 2005 and 2006 are considered for the other sites. According to the inter-annual robustness of the surface soil moisture up-scaling relation on Agoufou, eliminating 2005 data for Agoufou does not introduce any bias in the selected data set. It also equilibrates the number of transect measurements between Agoufou and the other sites. Accordingly, 21 transect measurements are available, of which 9 for Agoufou and 12 for the other sites (Table 3). For each transect, the temporally collocated surface soil moisture of the station of the considered site is compared to the transect value. Based on the 21 transects defined above, the multi-site $1 \mathrm{~km}$ up-scaling relation is determined to be:

$$
S S M_{\text {tra } 1 k m}=-0.52332+1.2995 \times S S M_{\text {staloc }}
$$

Figure 6 (left panel) shows the correspondence between the kilometer scale volumetric surface soil moisture measured from transect measurements and the volumetric 
the soil moisture extrapolated from corresponding local stations. Statistical results are presented in Table 4 . Although the dispersion $(R M S E=2.2 \%)$ is larger than that obtained at the single-site scale for the Agoufou and Bangui Mallam sites $(0.9 \%$ and $1.6 \%$ respectively), high correlation value $(R=0.82)$ and high efficiency $(E F F=0.66)$ clearly show good skill of this up-scaling relation to describe the $1 \mathrm{~km}$ volumetric surface soil moisture on the different coarse textured sites of the Gourma region. The robustness of the up-scaling relation at the multi-site scale indicates that surface soil moisture scaling characteristics are similar on the different coarse textured sites considered at meso-scale.

As mentioned above for the Bangui Mallam site (Figure 4), higher values of surface soil moisture are associated to higher values of absolute surface soil moisture variability. This relation between surface soil moisture and its spatial variability is investigated at the multi-site scale in Figure 6 (right panel). With a correlation of $R=0.82$, it is shown to be representative at the meso-scale, where all coarse textured sites are considered.

[Fig. 6 about here.]

The multi-site results presented above indicate that (i) the up-scaling relation given in equation 4 describes the $1 \mathrm{~km}$ scale volumetric surface soil moisture from any station of the meso-scale site with an averaged accuracy of $2.2 \%$, and that (ii) characteristics of surface soil moisture variability are similar for the different sites of the meso-scale window, with a $R=0.82$ correlation obtained between surface soil moisture and its spatial variability at $1 \mathrm{~km}$.

This underlines the high degree of representativity of the soil moisture stations for the kilometer scale. The result also suggests highly robust scaling relation of surface soil moisture. It justifies the approach to use a unique multi-site relation for extrapolating kilometer scale soil moisture for each coarse textured site equipped with a soil moisture station. The stability of these relationships across period longer 
than 2 years needs to be confirmed for future up-scaling applications. But for the considered years 2005 and 2006 this data set is shown to be suitable to validate of satellite products with ground station measurements (Gruhier et al. 2008; Zribi et al. this issue; Baup et al. 2008).

\subsection{Hydrological transect over the Agoufou site}

In addition to the $1 \mathrm{~km}$ transect performed on different sites, an hydrological transect was defined. This transect cuts across 7 catchments located within and next to the Agoufou local site. It is $1255 \mathrm{~m}$ long and not straight in order to follow the landscape features. Measurements of surface soil moisture (every 10m) along this transect was repeated 10 times in 2006 as indicated in Table 3. The elevation was assessed by means of a Global Positioning System, so that surface soil moisture variations are monitored in relation with topography information. Figure 7 shows surface soil moisture monitored along this transect at 4 different dates, just after rain on 19 August 2006 am and pm, and a few days before, on August 13 and 15 where no rainfall occurrence led to drying conditions. Topography (elevation in $\mathrm{m}$ ) is indicated on the bottom panel.

[Fig. 7 about here.]

Hydrological transect measurements aim at studying hydrological processes at different levels of the hillslope. Although they are limited to surface soil moisture, they provide complementary information compared to the three local stations of Agoufou which provide a complete vertical profile. Figure 7 qualitatively shows the influence of topography on the surface soil moisture value. In particular, persistent higher soil moisture values are observed near 500m, $875 \mathrm{~m}, 1200 \mathrm{~m}$ which all correspond to low elevation areas. At $1200 \mathrm{~m}$ there is a relative elevation minimum. It is not very pronounced in the direction of the transect but more important in the orthogonal 
direction. This explains the maximum soil moisture at this location. The correlation values, $\mathbf{R}$, between the SSM and the elevation are provided in the figure. They show that the surface soil moisture profile along the transect is negatively correlated to the elevation. This indicates that relatively wet condition are encountered in low elevation areas, while soil is getting dryer when elevation increases. These significant negative correlation values also indicate limited precipitation heterogeneities along the transect. The negative correlation is stronger for wet conditions than for dry conditions. This shows that for wet conditions the soil water distribution along the transect is largely related to the soil topography. For dryer soils the negative correlation is less strong which indicates that other processes, such as evapotranspiration or slight variations in soil texture, also influence the spatial distribution of surface soil moisture. However negative correlation values persist for a large range of soil moisture conditions from very wet (19 August am, a few hours after precipitation) to very dry conditions (15 August, after 10 days without rain).

Figure 8 displays the amplitude of the Discrete Fourier Transform (DFT) of the surface soil moisture and the soil elevation along the hydrological transect. The DFT represents the partitioning of the sample variance into spatial frequency components (Greminger et al., 1985). In Figure 8 DFTs are obtained with a Hamming window. They are represented on a logarithmic scale and expressed in terms of spatial period. The soil moisture DFTs are provided for 3 of the 4 cases considered in Figure 7, which allow the consideration of different soil moisture conditions. For the clarity of the figure the spectrum for the intermediate case of August 19pm is not shown. Process scales occur at spectral peaks, whereas spectral gaps represent spatial scales with minimum spectral variance. The dominant spectral peaks shown for the soil elevation are dominated by long wavelengths (spatial period larger than 100m). The dominant periods are the transect length, $250 \mathrm{~m}$ (extending from $180 \mathrm{~m}$ to $300 \mathrm{~m}$ ) and $100 \mathrm{~m}$. The variability of soil moisture at long wavelength is in relatively good agreement with that of soil elevation. For wet conditions, significant peaks are shown for 
periods of $100 \mathrm{~m}$ and $200 \mathrm{~m}$ in agreement with the soil elevation variability. For dryer soil conditions (Aug. 15), these two peaks are still characterising the soil moisture variability but their amplitude and spatial extention are reduced.

[Fig. 8 about here.]

Much less agreement between topography and soil moisture is shown for short spatial periods (below $80 \mathrm{~m}$ ). This indicates that surface soil moisture variations at smaller spatial scales are less related to the topography than larger scale variations. It is also clear from Figure 8 that smaller scale surface soil moisture variations are of lower amplitude than variations at larger scale.

\section{Temporal stability of the Gourma soil moisture network}

In this section the representativity of the ground soil moisture station is investigated further by the means of Mean Relative Difference method. Built on the Vachaud et al. (1985) approach, $M R D_{i}$ is computed for each station $i$, as:

$$
M R D_{i}=\frac{1}{t} \sum_{j=1}^{t} \frac{S S M_{i, j}-\overline{S S M_{j}}}{\overline{S S M_{j}}}
$$

where $j$ is the time step, $t$ is the number of time steps, $S S M_{i, j}$ is the surface soil moisture of station $i$ at the time step $j, \overline{S S M_{j}}$ is the surface soil moisture averaged over the different stations at the time step $j$. The value of $M R D_{i}$ quantifies the agreement of SSM between station $i$ and the stations average. Its temporal standard deviation $S T D_{i}$, computed from $\left(S S M_{i, j}-\overline{S S M_{j}}\right) /\left(\overline{S S M_{j}}\right)$ time series, quantifies the agreement of surface soil moisture between the local station $i$ and the stations average in term of temporal variability.

This method is applied for the whole year 2006, to the Agoufou super site (Figure 1, right): the three stations of Agoufou are considered together with those of Bangui 
Mallam and Eguérit. These 5 stations encompass an area of about $25 \mathrm{~km} \times 25 \mathrm{~km}$, with soil surface types representative of $90 \%$ of the Gourma meso-scale site. Soil moisture data from each station are weighted according to the soil type distribution over the super site.

[Fig. 9 about here.]

Results of the MRD analysis on the Gourma super site are plotted in Figure 9 on a circle plot where the angle deviation from $45^{\circ}$ gives the MRD value of each station and the radius indicates its standard deviation (STD). This figure clearly shows that the Agoufou middle of hillslope station, for which the MRD value is close to zero, captures almost perfectly the mean annual value of the super site averaged surface soil moisture. Lower values of MRD for the stations located at the top of the hillslope in Agoufou and in Bangui Mallam indicate that these sites are generally dryer than the super site average. In contrast Eguérit and Agoufou Bottom have higher values of their surface soil moisture MRD which indicate that they are wetter than the super site average. These results are in agreement with the qualitative features shown in Figure 2.

Beside its absolute value, surface soil moisture temporal variability is of highest importance. Standard deviation of MRD indicates for each station its representativity at the super site scale in terms of soil moisture temporal variability. The Agoufou top of hillslope station is shown to have the lowest STD (0.21), which shows that is in best agreement with SSM variability at the super site scale. The Bangui Mallam STD is 0.28 , showing this site provides a good estimate of SSM variability as well. STD values of the three other stations are much higher with more than 0.4 for Agoufou middle of hillslope, more than 0.6 for Agoufou bottom of hillslope and almost 0.7 for Eguérit. This indicates that, although surface soil moisture is lowbiased for two of these stations, its temporal variability does not match with that 
observed at the super site scale.

The Agoufou top of hillslope station, with lowest STD and reasonable MRD, is the most representative station of the surface soil moisture at the Agoufou super site scale. This is in agreement with the up-scaling analysis conducted in the previous section at the kilometer scale where the same station is shown to be representative of the kilometer scale SSM through a linear regression.

\section{Conclusion}

This paper presents the Gourma (Mali) meso-scale soil moisture network which has been implemented in the framework of the AMMA project. This soil moisture network is a component of the AMMA's multidisciplinary and multi-scale observing system (Redelsperger et al. 2006). Initially implemented in the context of the Enhanced Observing Period (EOP, 2005-2007), it has been extended to the Long term Observing Period (LOP, 2005-2009) of AMMA.

The Gourma soil moisture network aims at documenting soil moisture dynamics in the sahelian region of Mali, for a large range of temporal and spatial scales at which land surface processes and surface-atmosphere interaction occur. To this end a set of 10 soil moisture stations is spanning $2^{\circ}$ between $15^{\circ} \mathrm{N}$ and $17^{\circ} \mathrm{N}$. Different types of soil surfaces are instrumented according to their spatial distribution over the meso-scale site. Observing results from the 2005-2006 period are presented in this paper.

Soil moisture measurements on coarse textured sites, which represent $65 \%$ of the meso-scale area, clearly show that the temporal surface soil moisture dynamics is highly influenced by the climatic condition and the rainfall variability along the North-South transect (section 3). Northern stations of Bamba and In Zaket are characterised by lower soil moisture values and lower time variability, while stations located within the super site depict higher soil moisture values and variability. Soil 
moisture dynamics is also strongly influenced by surface properties (soil and vegetation types, topography). Flat rocky-loam surfaces, which represent $28 \%$ of the meso-scale site are shown to be characterised by a relatively slow temporal variability. Clay area, covered by acacia forest is distinguished by its high values of soil moisture, due to the soil texture and to the soil flooding during the monsoon season. Beside these differences in soil moisture dynamics along the N-S gradient and for different surface types, all the soil moisture stations of the Gourma network show a 2005-2006 inter-annual variability which is characterised by a later monsoon in 2006. This is in agreement with atmospheric observations described in Janicot et al. (2008).

A case study is investigated, based on Bangui Mallam measurements, to address the vertical structure of soil moisture dynamics on coarse textured soils (Figure 3). Soil water budgets are computed for soil boxes between 0-1m and 1-2m, and compared to precipitation input for a 6-day period between July 28 and August 22006 (DoY 209-214). Fast soil water infiltration is depicted for the first meter of soil. After the $61.5 \mathrm{~mm}$ precipitation event that occurred on DoY 210, the wetting front is shown to reach $80 \mathrm{~cm}$ depth 1.5 days after the rain. The $1-2 \mathrm{~m}$ soil water content significantly increased about 2.75 day after a strong precipitation event occurred, whereas the 0-1m soil moisture budget already decreased. While the first meter of soil is characterised by very fast response of soil moisture to the atmospheric forcing, deeper soil is shown to respond at the seasonal time scale to atmospheric forcing and resulting land surface processes (infiltration and water uptake).

An up-scaling analysis of surface soil moisture is conducted in this paper, based on kilometer scale transect measurements performed in 2005 and 2006 on different coarse textured sites of the meso-scale area (section 4). An up-scaling relationship is determined and shown to be highly suitable to extrapolate kilometer scale surface soil moisture on the Bangui Mallam site for 2006 (equation 1). The accuracy is shown to be $1.6 \%$, with a $\mathbf{0 . 8 9}$ correlation with transect measurements. The high 
number of transect measurements performed at the Agoufou local site in 2005 and 2006 allows showing the inter-annual stability of the up-scaling relation for this site. Accordingly, equation 2 extrapolates surface soil moisture at the scale of $1 \mathrm{~km}$ from the Agoufou top of hillslope station, with an accuracy better than $1 \%$ in volumetric soil moisture. Based on the 2006 data set, the Agoufou top of hillslope station is shown to be the most representative station to derive the kilometer scale surface soil moisture at the Agoufou site.

This paper shows that the relationship between surface soil moisture and its $1 \mathrm{~km}$ spatial variability is very stable among the different sites of the Gourma meso-scale for the two studied years. Due to this consistency among the sites, the use of an unique multi-site up-scaling relation is shown to be accurate within $2.2 \%$ (volumetric) to retrieve $1 \mathrm{~km}$ scale surface soil moisture from station measurements.

This paper introduces measurements performed along an hydrological transect where elevation measurements were also performed. Discrete Fourier Transform of surface soil moisture and soil elevation show that significant variations of surface soil moisture are dominated by spatial periods of $250 \mathrm{~m}$ and $100 \mathrm{~m}$. Same dominant periods are shown for the soil elevation, which indicates that the soil moisture spatial variability is related to the soil topography along the transect. Soil moisture variations at scales smaller than $80 \mathrm{~m}$ are of lower amplitude and less related to topography. More investigations are however required to address the relative role of land surface cover, soil texture class and precipitation variability on the small scale soil moisture variability.

Surface soil moisture scaling is investigated further in section 5, where the Mean Relative Difference approach is applied to the Gourma super site. The Agoufou top of hillslope station is shown to be the most representative of the surface soil moisture variability (lowest standard deviation of the MRD) at the super site scale. Consistency of the results at different scales, from local to kilometer and from local to super sites scale, and with different approaches (transects and MRD), indicates 
that up-scaling features of surface soil moisture are consistent at the three considered spatial scales (local, $1 \mathrm{~km}$, super site). Based on these preliminary results, additional measurements are required to address the relation between local, transect and super site measurements. Measurements along a $50 \mathrm{~km}$ transect were performed in 2006 and 2007 (not shown here) and will be addressed in further studies.

The robustness of the surface soil moisture up-scaling relation for different coarse textured sites indicates that the Gourma meso scale soil moisture network is highly suitable for remote sensing and land surface modelling applications for which soil moisture is also required at larger scale than the station measurement. With the Bénin and Niger soil moisture networks, the Gourma soil moisture network has been selected to be a validation site for the future SMOS (Soil Moisture and Ocean Salinity Mission) (Kerr et al. 2001). Coordinated measurements of soil moisture, meteorological and flux measurements as well as vegetation measurements over the meso-scale site, makes the Gourma meso-scale soil moisture network of high interest in many research areas related to land surface processes and land-surfaceatmosphere interaction studies.

Acknowledgements. This research was funded by the API (Action Programmée Inter-organisme) in the framework of the AMMA-CATCH ORE (Couplage de l'Atmosphère Tropicale et du Cycle Hydrologique - Observatoire de Recherche sur l'Environnement) Program initiated by the French Ministry of Research. The authors thank Anton Beljaars and two anonymous reviewers for their useful comments on the manuscript.

\section{References}

[Baup et al. 2007] Baup, F., E. Mougin, P. de Rosnay, F. Timouk, and I. Chênerie, 2007: Surface soil moisture estimation over the AMMA Sahelian site in Mali using ENVISAT/ASAR data. Remote sens. environ., 109(4),473-481. 
[Boone et al. 2008] Boone, A., P. de Rosnay, G. Balsamo, A. Beljaars, F. Chopin, B. Decharme, C. Delire, A. Ducharne, S. Gascoin, F. Guichard, Y. Gusev, P. Harris, L. Jarlan, L. Kergoat, E. Mougin, O. Nasonova, A. Norgaard, T. d'Orgeval, C. Ottlé, I. Poccard-Leclercq, J. Polcher, I. Sandholt, S. Saux-Picart, C.M. Taylor, and X. Xue, 2008: The AMMA Land Surface Intercomparison Project (ALMIP), Bull. Amer. Meteorol. Soc, submitted.

[Bosch et al. 2006] Bosch, D.D., V. Lakshmi, T.J. Jackson, M. Choi, and J.M. Jacobs, 2006: Large scale measurements of soil moisture for validation of remotely sensed data: Georgia soil moisture experiment of 2003 Journal of Hydrology, 123.doi:10.1016/j.jhydrol.2005.08.024.

[Calvet et al. 1996] Calvet, J.-C., A. Chanzy, and J.-P. Wigneron, 1996: Surface temperature and soil moisture retrieval in the Sahel from airborne multifrequency microwave radiometry Geoscience and Remote Sensing, IEEE Transactions on IEEE Trans. Geosc. Remote Sens., 34 (2), pp 588-600.

[Chanzy et al. 1997] Chanzy, A., T.J. Schmugge, J.-C. Calvet, Y. Kerr, P. van Oevelen, O. Grosjean, and J.R. Wang, 1997: Airborne microwave radiometry on a semi-arid area during HAPEX-Sahel Journal of Hydrology, HAPEXSAHEL special issue, 188-189. pp 285-309

[Cosh et al. 2004] Cosh, M. H., T. J. Jackson, R. Bindlish, and J. H. Prueger, 2004: Watershed scale temporal and spatial stability of soil moisture and its role in validating satellite estimates. Remote sens. environ., 92, pp 427-435.

[De Lannoy et al. 2007] De Lannoy, G.J.M., P. Houser, and N. Verhoest, and V. Pauwels, and T Gish, 2007: Upscaling of point soil moisture observations to field averages at the OPE3 site. Journal of Hydrology, 343(1-2),pp 1-11, doi:10.1016/j.jhydrol.2007.06.004.

[Famiglietti et al. 1999] Famiglietti, J., J. Devereaux, C. Laymon, T. Tsegaye, P. Houser, T. Jackson, S. Graham, M. Rodell, and P. van Oevelen, 1999: Groundbased investigation of soil moisture variability within remote sensing footprints 
during the Southern Great Plains 1997 (SGP97) hydrology experiment. Water Resour. Res., 35(6), pp 1839-1851.

[Frappart et al. 2009] Frappart, F., P., Hiernaux, F., Guichard, E., Mougin, L., Kergoat, M., Arjounin, F., Lavenu, M., Koité, J.-E., Paturel, T., and Lebel, 2009: Rainfall regime over the Sahelian climate gradient in the Gourma, Mali. Journal of Hydrology, this issue.

[Gee and Bauder 1986] Gee, G., and J. Bauder, 1986: Particule size analysis. A. Klute (Ed.) Method of size analysis. Parti I, 2nd ed., Agronomy Monograph.9, American Society of Agronomy, Madison, WI, 4,383-411.

[Greminger et al. 1985] Greminger, P.J., Y.K. Sud, and D.R. Nielsen, 1985: Spatial variability of field-measured soil-water characteristics, Soil Sci. Soc. Am. J., 49(5), 1075-1082.

[Gruhier et al. 2008] Gruhier, C., P. de Rosnay, Y. Kerr, E. Mougin, E. Ceschia, C. J.-C., and P. Richaume, 2008: Evaluation of AMSR-E Soil Moisture Products Based on Ground Soil Moisture Network Measurements. Geophy. Res. Letters, 35, L10405, doi:10.1029/2008GL033330.

[Hiernaux et al. 2009] Hiernaux, P., E. Mougin, L. Diarra, N. Soumaguel, F. Lavenu, Y. Tracol, and M. Diawara, 2009: Sahelian rangeland response to changes in rainfall over two decades in the Gourma region, Mali. Journal of Hydrology, this issue.

[Janicot et al. 2008] Janicot, S., A. Ali, A. Asencio, G. Berry, O. Bock, B. Bourles, G. Ganiaux, F. Chauvin, A. Deme, L. Kergoat, J.-P. Lafore, C. Lavaysse, T. Lebel, B. Marticorena, F. Mounier, J.-L. Redelsperger, C. Reeves, R. Roca, P. de Rosnay, B. Sultan, C. Thorncroft, M. Tomasini, and A. forcasters team, 2008: Large scale overview of the summer monsoon over West and Central Africa during AMMA field experiment in 2006. Ann. Geophys., 26(9), pp2569-2595.

[Jackson et al. 2003] Jackson, T., R. Bindlish, M. Klein, A.J. Gasiewski, and E. Njoku, 2003: Soil moisture retrieval and AMSR-E validation using an airborne 
microwave radiometer in SMEX02, Proceedings of IEEE International Geoscience and Remote Sensing Symposium 2003, IGARSS'03., Vol.1, pp.401-403.

[Jackson et al. 1997] Jackson, T., P. O'Neill and C.T. Swift, 1997: Passive microwave observation of diurnal surface moil moisture, IEEE Trans. Geosc. Remote Sens., 35, pp. 1210-1222.

[Jarlan et al. 2008] Jarlan, L., G. Balsamo, S. Lafont, A. Beljaars, J.-C. Calvet, and E. Mougin, 2008: Analysis of leaf area index in the ecmwf land surface scheme and impact on latent heat and carbon fluxes: Application to west africa. J. Geophys. Res., in press.

[Kerr 2007] Kerr, Y. H., 2007: Soil Moisture from space: Where we are ? Hydrogeology journal, 15,117-120.

[Kerr et al. 2001] Kerr, Y. H., P. Waldteufel, J.-P. Wigneron, J.-M. Martinuzzi, J. Font, and M. Berger, 2001: Soil moisture retrieval from space: the soil moisture and ocean salinity (SMOS) mission. IEEE Trans. Geosc. Remote Sens., 39 (8),1729-1735.

[Kim and Barros 2002] Kim, G., and A. Barros, 2002: Space-time characterization of soil moisture from passive microwave remotely sensed imagery and ancillary data. Remote sens. environ., 81, 393-403.

[Koster et al. 2004] Koster, R. D., P. Dirmeyer, Z. Guo, G. Bonan, P. Cox, C. Gordon, S. Kanae, E. Kowalczyk, D. Lawrence, P. Liu, C. Lu, S. Malyshev, B. McAvaney, K. Mitchell, D. Mocko, T. Oki, K. Oleson, A. Pitman, Y. Sud, C. Taylor, D. Verseghy, R. Vasic, Y. Xue, and T. Yamada, 2004: Regions of strong coupling between soil moisture and precipitation. Sciences, 305, pp1138-1140.

[Le Dantec et al. 2006] Le Dantec, V., J. Seghieri, E. Mougin, P. Hiernaux, F. Timouk, V. Demarez, L. Kergoat, F. Lavenu, P. de Rosnay, M.-N. Mulhaupt, N. Soumagel, A. Moctar, C. Damesin, J. Bennie, L. Mercado, D. Epron, R. Dupont, and S. D., 2006: Carbon and Water Exchanges at the Gourma site (Mali). SOP Debriefing and Preparation of Process Studies, Toulouse, France. 
[Lebel and Ali 2009] Lebel, T., and A. Ali, 2009: Recent trends in the Central Sahel rainfall regime (1990 - 2007). Journal of Hydrology, this issue.

[Le Morvan et al. 2008] Le Morvan, A., M. Zribi, N. Baghdadi, A. Chanzy, 2008: Soil Moisture Profile Effect on Radar Signal Measurement. Sensors. 8, pp 256270.

[Lloyd 1997] Lloyd, C.R., P. Bessemoulin, F.D. Cropley, A.D. Culf, A.J. Dolman, J. Elbers, B. Heusinkveld, J.B. Moncrieff, B. Monteny, and A. Verhoef, 1997: A comparison of surface fluxes at the HAPEX-Sahel fallow bush sites. Journal of Hydrology, HAPEX-SAHEL special issue, 188-189 pp 400-425.

[Magagi and Kerr 1997] Magagi, R. and Y.H Kerr, 1997: Retrieval of soil moisture and vegetation characteristics by use of ERS-1 wind scatterometer over arid and semi-arid areas Journal of Hydrology, HAPEX-SAHEL special issue, 188-189, pp 361-384, doi:10.1016/S0022-1694(96)03166-6 .

[Monteny et al. 1997] Monteny, B.A., J.-P. Lhomme, A. Chehbouni, D. Troufleau, M. Amadou, M. Sicot, A. Verhoef, S. Galle, F. Said, and C.R. Lloyd 1997: The role of the Sahelian biosphere on the water and the CO2 cycle during the HAPEXSahel experiment Journal of Hydrology, HAPEX-SAHEL special issue, 188-189, pp 516-535, doi:10.1016/S0022-1694(96)03191-5.

[1] Mougin, E., P. Hiernaux, L. Kergoat, M. Grippa, P. de Rosnay, F. Timouk, V. Le Dantec, V. Demarez, M. Ajournin, F. Lavenu, N. Soumaguel, E. Ceschia, B. Mougenot, F. Baup, F. Frappart, P.L. Frison, J. Gardelle, C. Gruhier, L. Jarlan, S. Mangiarotti, B. Sanou, Y. Tracol, F. Guichard, V. Trichon, L. Diarra, A. Soumaré, M. Koité, F. Dembélé, C. Lloyd, N. P. Hanan, C. Damesin, C. Delon, D. Sercca, C. Galy-Lacaux, J.Seghiéri, S. Becerra, H. Dia, F. Gangneron, P. Mazzega, 2009: The AMMA-CATCH Gourma observatory site in Mali: Relating climatic variations to changes in vegetation, surface hydrology, fluxes and natural resources. Journal of Hydrology, this issue. 
[Nicholson et al. 1997] Nicholson, S.E., J A. Marengo, J. Kim, A.R. Lare, S. Galle and Y.H. Kerr, 1997: A daily resolution evapoclimatonomy model applied to surface water balance calculations at the HAPEX-Sahel supersites Journal of Hydrology, HAPEX-SAHEL special issue, 188-189, doi:10.1016/S0022-1694(96)03178-2 , pp 946-964 .

[Redelsperger et al. 2006] Redelsperger, J.-L., C., Thorncroft, A., Diedhiou, T., Lebel, D., Parker, and J., Polcher, 2006: African Monsoon, Multidisciplinary Analysis (AMMA): An International Research Project and Field Campaign. Bull. Amer. Meteorol. Soc, 87(12), pp 1739-1746.

[Rüdiger et al. 2007] Rüdiger, C., G. Hancock, M.H. Hemakumara, B. Jacobs, J. Kalma, C. Martinez, M. Thyer, J.P. Walker, T. Wells, and G.R. Willgoose, 2007: Goulburn River experimental catchment data set. Water Resources Research, 43, W10403, doi:10.1029/2006WR005837.

[Seghieri et al. 2009] Seghieri, J., A. Vescovo, K. Padel, R. Soubié, M. Arjounin, N. Boulain, P. de Rosnay, S. Galle, M. Gosset, A. Mouctar, C. Peugeot, F. Timouk, 2009: Relationships between climate, soil moisture and phenology of the woody cover in two sites located along the West African latitudinal gradient. Journal of Hydrology, this issue.

[Schmugge 1998] Schmugge, T., 1998: Applications of passive microwave observations of surface soil moisture. Journal of Hydrology, 212-213 pp 188-197.

[Taylor and Ellis 2006] Taylor, C., R. Ellis 2006: Satellite detection of soil moisture impacts on convection at the mesoscale, Geophy. Res. Letters, 33, L03404,doi:10.1029/2007GL030572.

[Taylor et al. 2007] Taylor, C., L. Kergoat, and P. de Rosnay 2007: Land Surface Atmosphere Interactions During the AMMA SOP CLIVAR Exchanges News Letter, 12, 2, N 41 April 2007.

[Timouk et al. 2009] Timouk, F., L. Kergoat, E. Mougin, C. Lloyd, E. Ceschia, P. de Rosnay, P. Hiernaux, V. Demarez, and C. Taylor, 2009: The Response 
794 of sensible heat flux to water regime and vegetation development in a central 795 Sahelian landscape. Journal of Hydrology, this issue.

796 [Vachaud et al. 1985] Vachaud, G., A. Passerat De Silans, P. Balabanis, and 797 M. Vauclin, 1985: Temporal Stability of Spatially Measured Soil Water Prob798 ability Density Function. Soil Sci. Soc. Am. J., 49, 822-828.

[Zribi et al. 2009] Zribi, M., M. Pardé, P. de Rosnay, F. Baup, L. Descroix, C. Ottlé, and B. Decharme, 2009: ERS Scatterometer surface soil moisture analysis of two sites in the south and north of the Sahel region of West Africa. Journal of Hydrology, this issue. 
1 Location of the 10 automatic soil moisture stations (white stars), for the Gourma meso-scale site (left) and for the super-site (right).

2 Volumetric surface (5cm) soil moisture (in \%), evolution for 2005 and 2006 for eight different sites located along the North-South gradient of the Gourma region of Mali.

3 Top panel: temporal dynamics of volumetric soil moisture at different soil depths at Bangui Mallam in 2006. Middle panel shows the vertical profiles of volumetric soil moisture at different dates, before rain (DoY 209, July 28), after a major rainfall event (DoY 210), and after two additional rainfall events (DoY 214, August 2). Bottom panel depicts, for DoY 202 to DoY 214, the temporal evolution of the accumulated precipitation (black line), vertically integrated soil water content on the $0-1 \mathrm{~m}$ soil layer (dotted line) and on the 1-2m soil layer (dashed line).

4 Transect measurements of surface soil moisture at three different dates in August 2006. For each date, the mean value of surface soil moisture (SM) and its standard deviation (STD) are indicated.

5 Surface soil moisture estimated at the $1 \mathrm{~km}$ scale from transect measurements (vertical axis) and from the local Agoufou top of hillslope station measurements to which was applied the equation 2 up-scaling relation (horizontal axis).

6 Multi-site transect measurements. On the left panel, surface soil moisture estimated at the $1 \mathrm{~km}$ scale from transect measurements on different coarse textured sites (vertical axis) and from the nearest stations measurements to which was applied the multi-site up-scaling relation equation 4 (horizontal axis). On the right panel, relation between transects surface soil moisture spatial variability and the averaged surface soil moisture values.

$7 \quad$ Surface soil moisture (top panel) and topography (bottom panel) along the hydrological transect. Four transects are shown here for different soil moisture conditions. Very wet conditions are shown on 19 August since a heavy rainfall event occurred a few hour before, on the $18^{\text {th }}$ August in the evening. 13 and 15 August are respectively 4 and 6 days after the rainfall event of the 9 August. 
8 Amplitude of the Discrete Fourier Transform of the topography (thick black line) and the surface soil moisture at 3 different dates (thin lines) for different soil moisture conditions indicated in Figure 7. The abscissa axe is the spatial period in meter. The amplitude is expressed in $m$ and in $m^{3} m^{-3}$ for the elevation and soil moisture respectively.

9 Mean Relative Difference (MRD) and its time Standard Deviation (STD) (see text, section 5) for the volumetric surface soil moisture of each of the five stations considered at the Agoufou super site scale compared to the site average. 


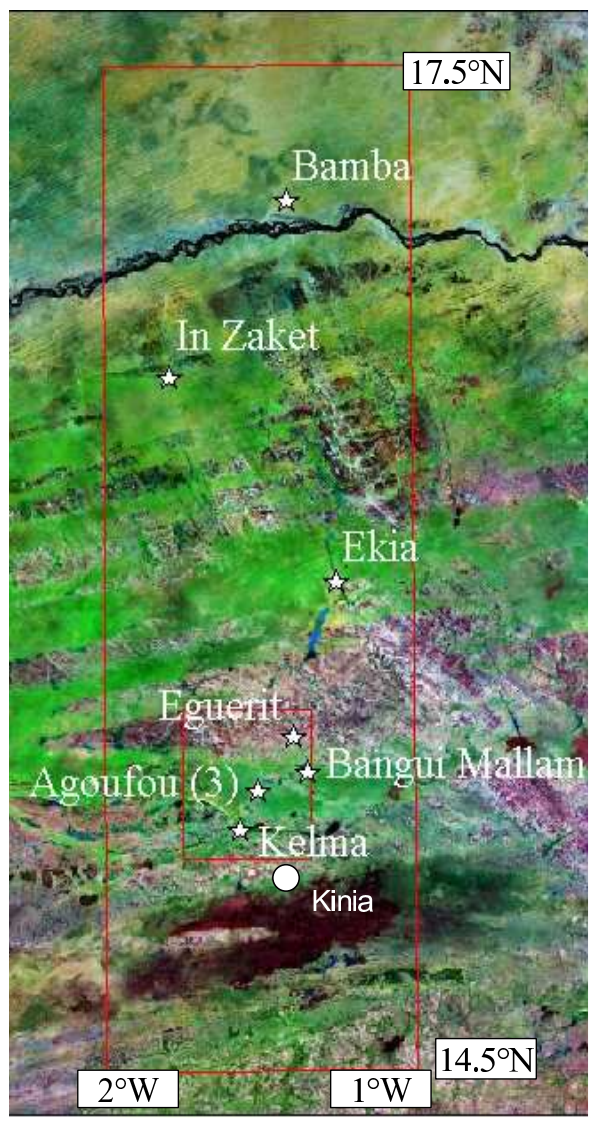

Gourma meso-scale site

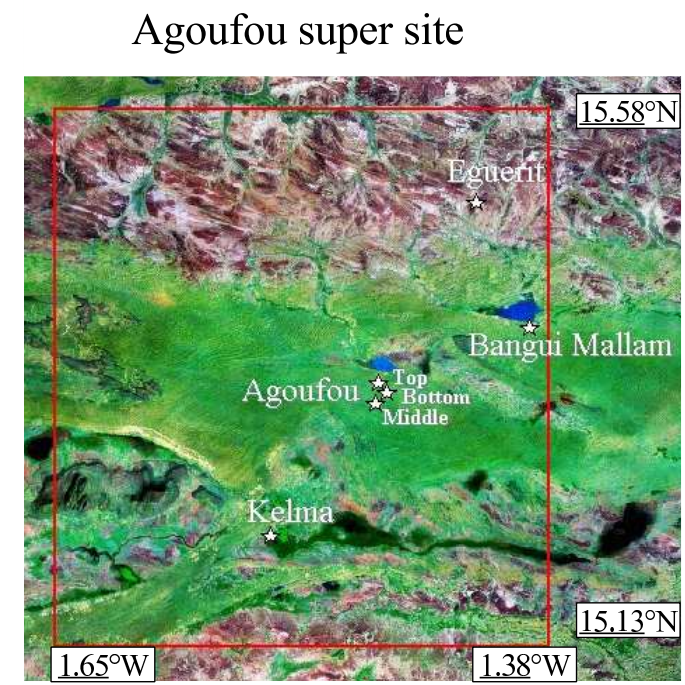

Fig. 1. Location of the 10 automatic soil moisture stations (white stars), for the Gourma meso-scale site (left) and for the super-site (right). 

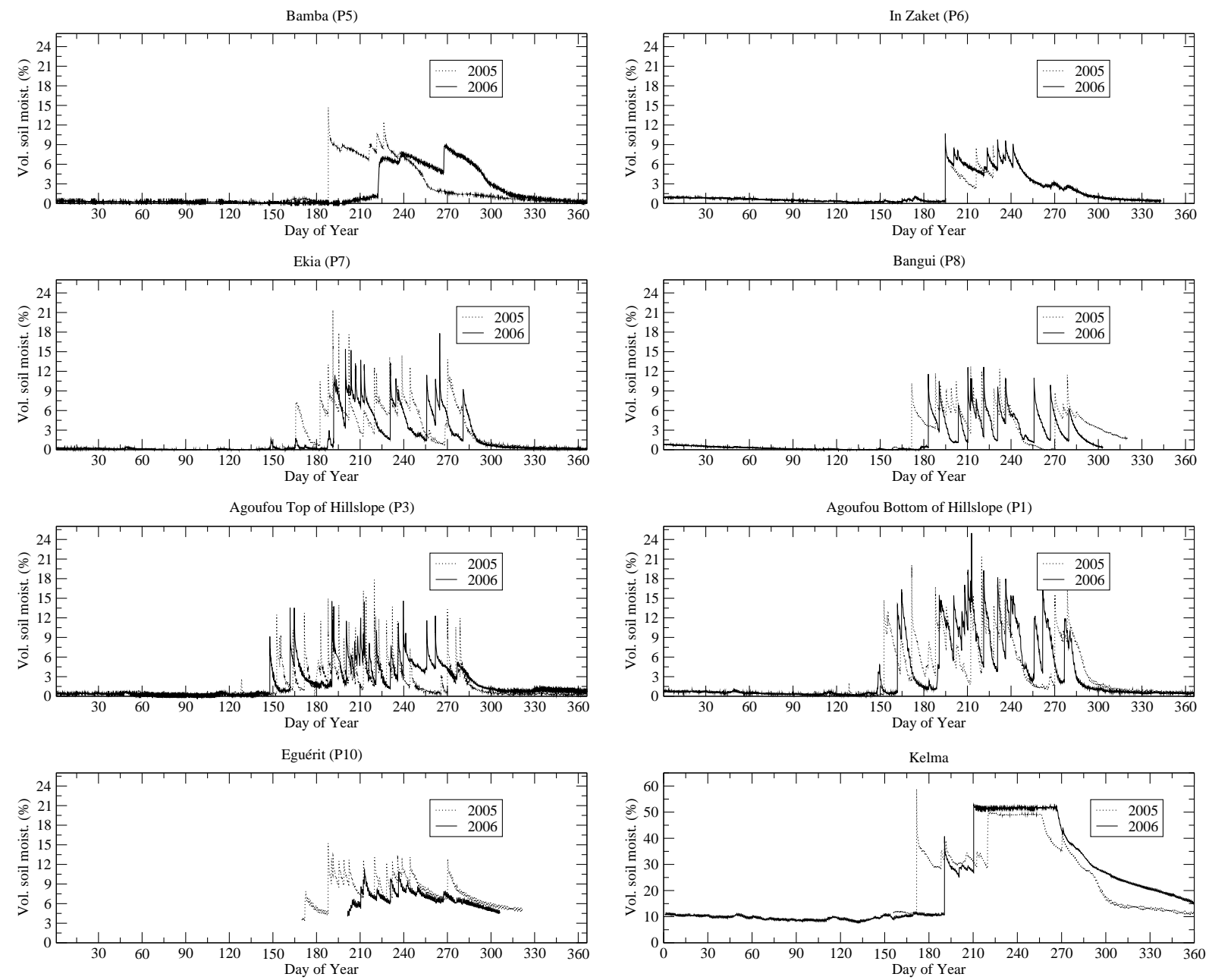

Fig. 2. Volumetric surface (5cm) soil moisture (in \%), evolution for 2005 and 2006 for eight different sites located along the North-South gradient of the Gourma region of Mali. 

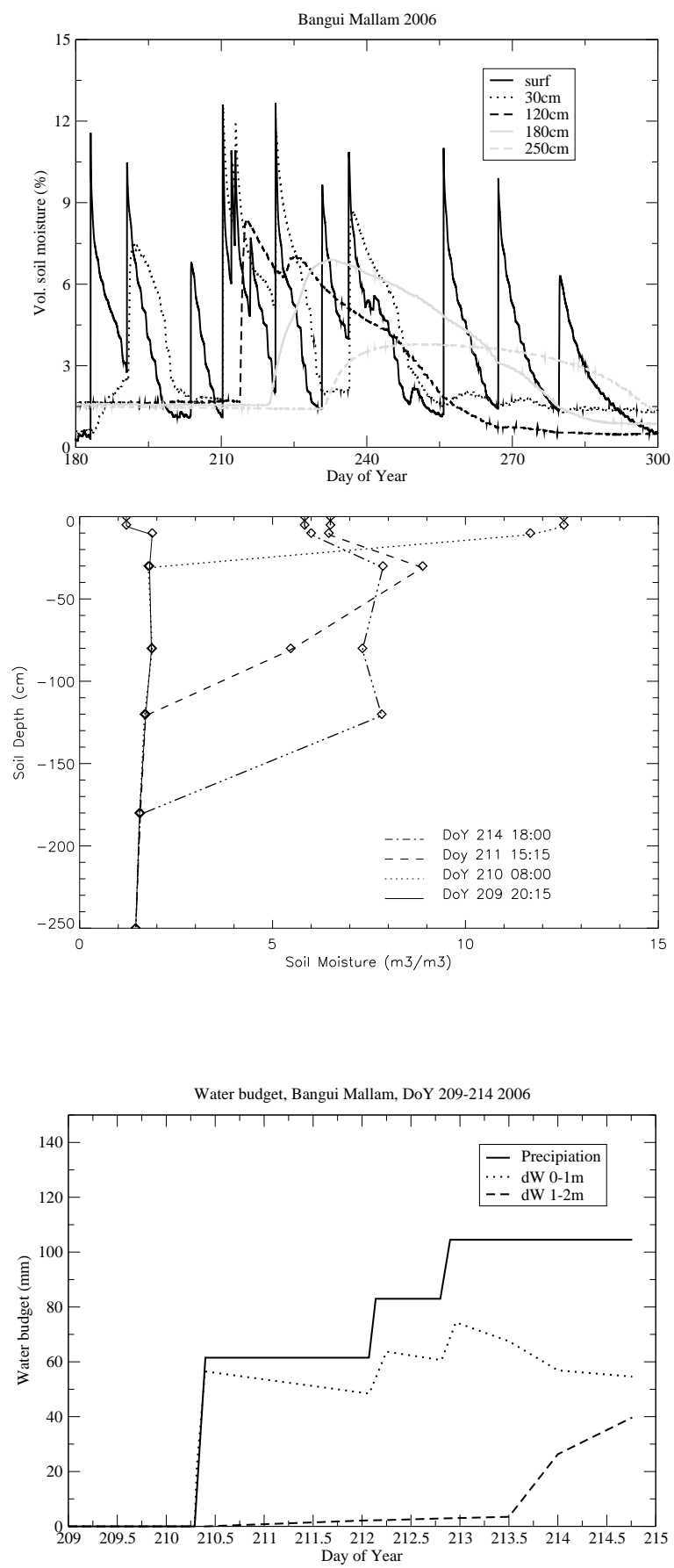

Fig. 3. Top panel: temporal dynamics of volumetric soil moisture at different soil depths at Bangui Mallam in 2006. Middle panel shows the vertical profiles of volumetric soil moisture at different dates, before rain (DoY 209, July 28), after a major rainfall event (DoY 210), and after two additional rainfall events (DoY 214, August 2). Bottom panel depicts, for DoY 202 to DoY 214, the temporal evolution of the accumulated precipitation (black line), vertically integrated soil water content on the $0-1 \mathrm{~m}$ soil layer (dotted line) and on the $1-2 \mathrm{~m}$ soil layer (dashed line). 


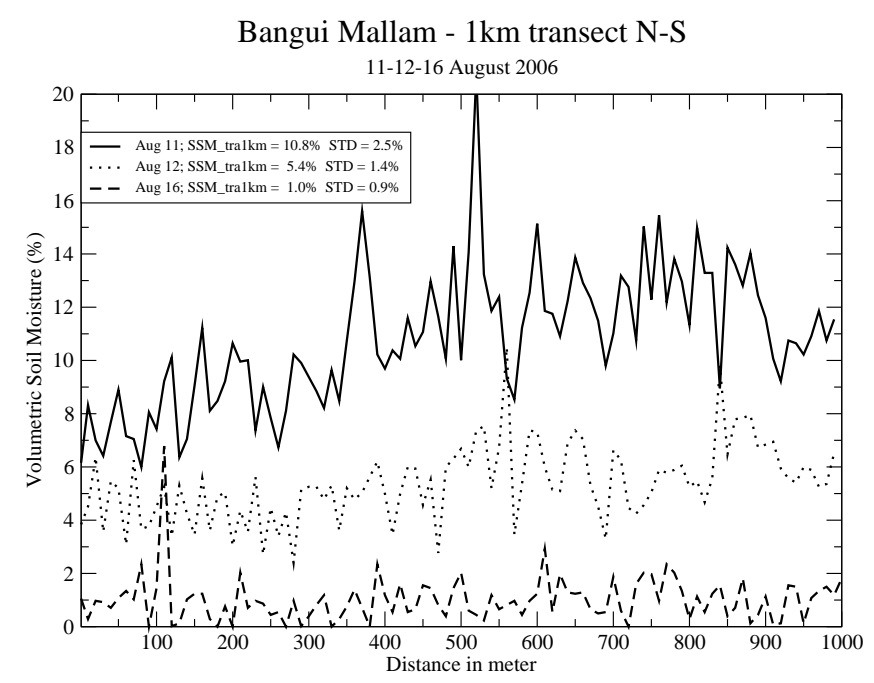

Fig. 4. Transect measurements of surface soil moisture at three different dates in August 2006. For each date, the mean value of surface soil moisture (SM) and its standard deviation (STD) are indicated. 


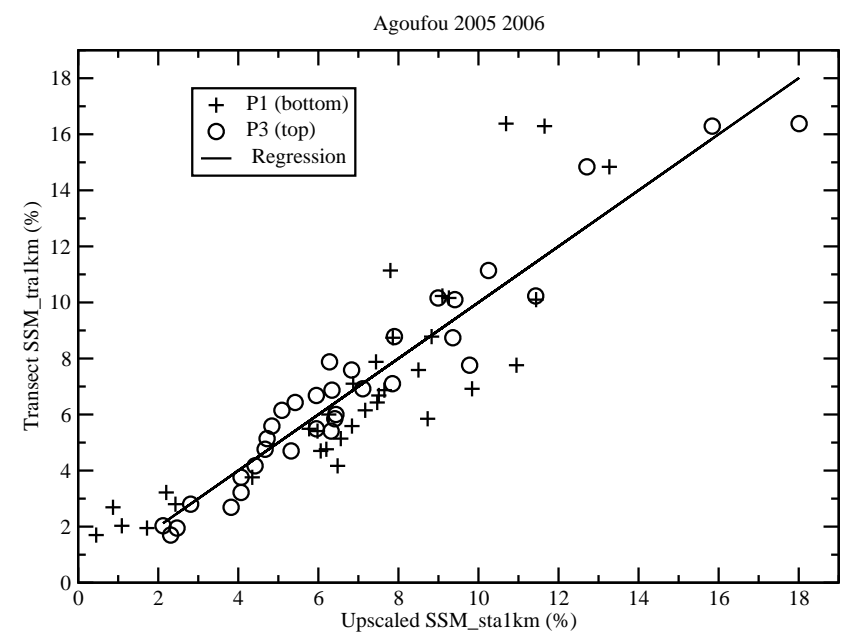

Fig. 5. Surface soil moisture estimated at the $1 \mathrm{~km}$ scale from transect measurements (vertical axis) and from the local Agoufou top of hillslope station measurements to which was applied the equation 2 up-scaling relation (horizontal axis). 

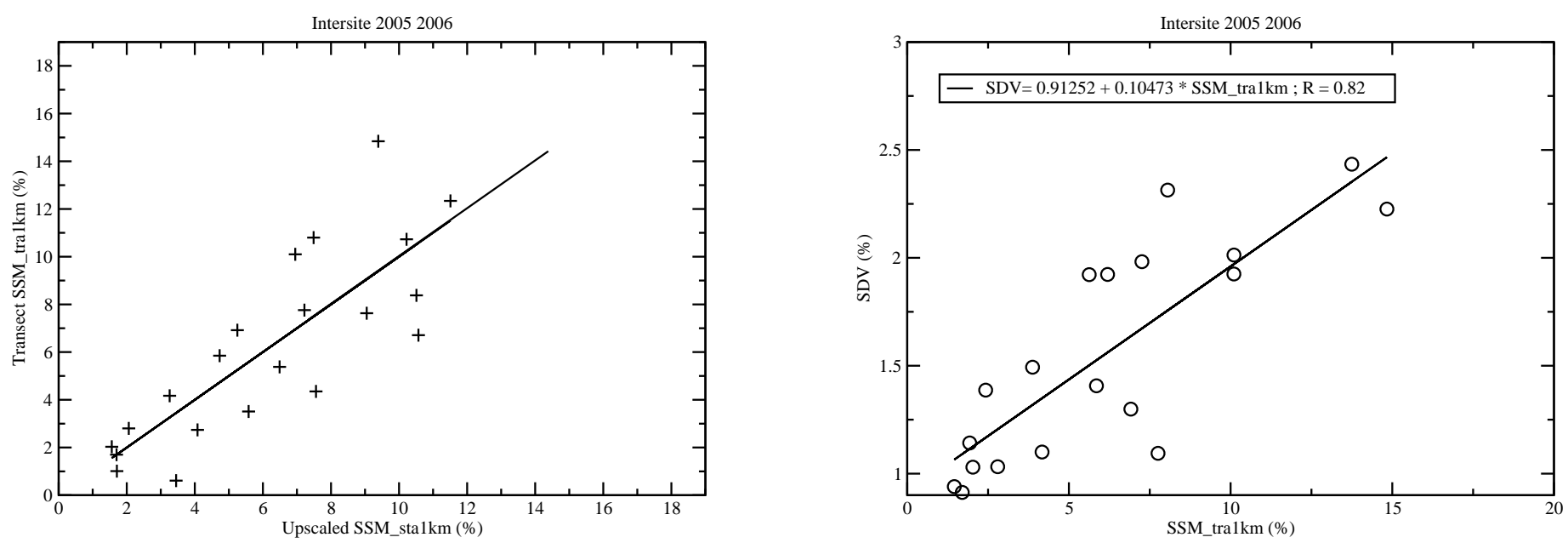

Fig. 6. Multi-site transect measurements. On the left panel, surface soil moisture estimated at the $1 \mathrm{~km}$ scale from transect measurements on different coarse textured sites (vertical axis) and from the nearest stations measurements to which was applied the multi-site up-scaling relation equation 4 (horizontal axis). On the right panel, relation between transects surface soil moisture spatial variability and the averaged surface soil moisture values. 
SITE 17 - hydrological transect
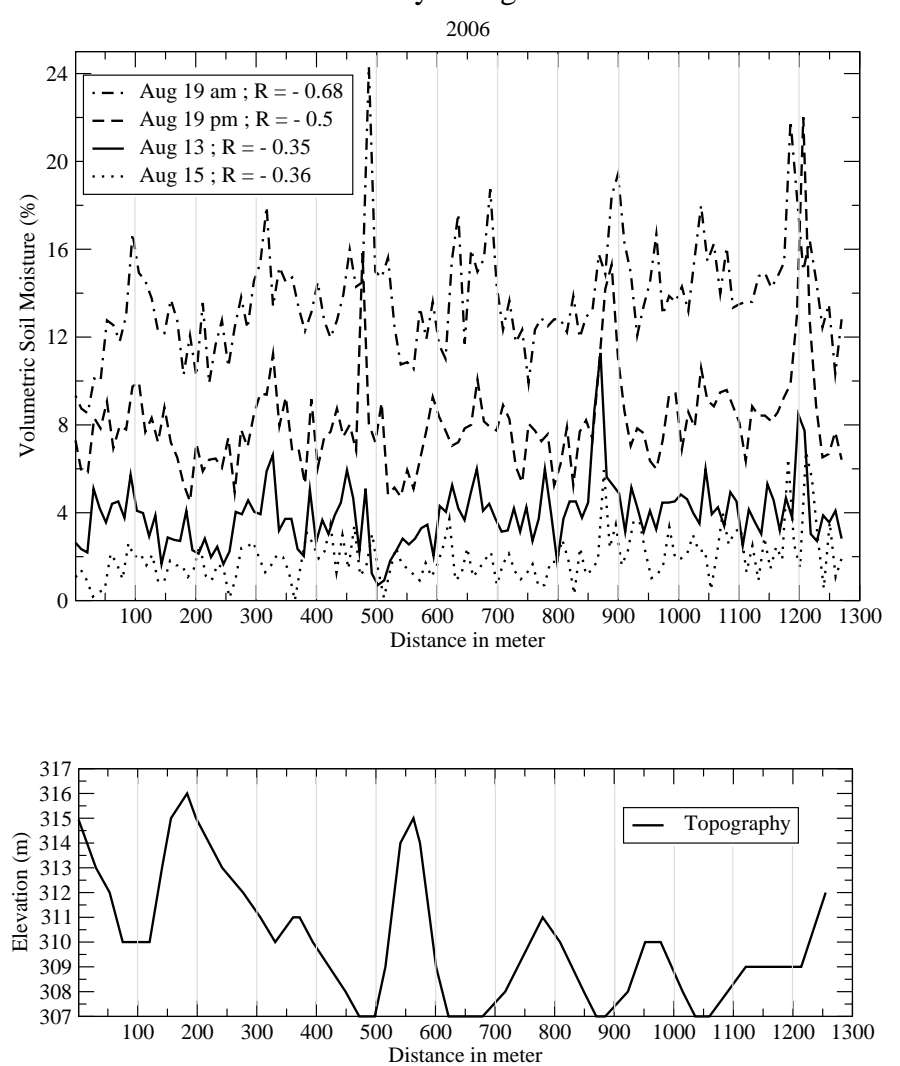

Fig. 7. Surface soil moisture (top panel) and topography (bottom panel) along the hydrological transect. Four transects are shown here for different soil moisture conditions. Very wet conditions are shown on 19 August since a heavy rainfall event occurred a few hour before, on the $18^{\text {th }}$ August in the evening. 13 and 15 August are respectively 4 and 6 days after the rainfall event of the 9 August. 


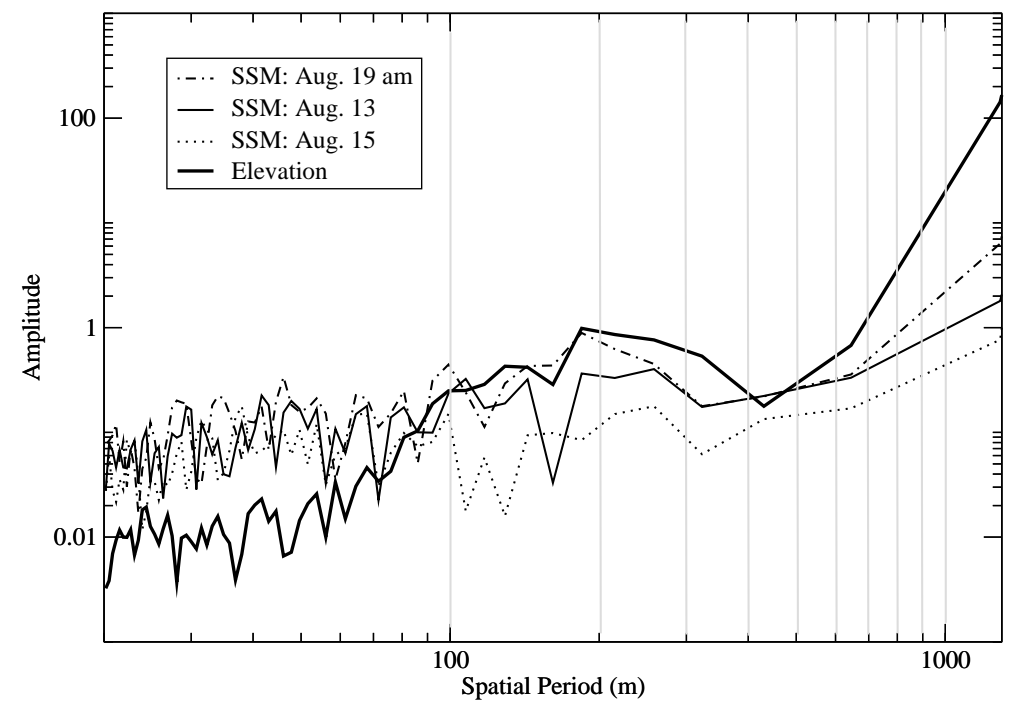

Fig. 8. Amplitude of the Discrete Fourier Transform of the topography (thick black line) and the surface soil moisture at 3 different dates (thin lines) for different soil moisture conditions indicated in Figure 7 . The abscissa axe is the spatial period in meter. The amplitude is expressed in $m$ and in $m^{3} m^{-3}$ for the elevation and soil moisture respectively. 


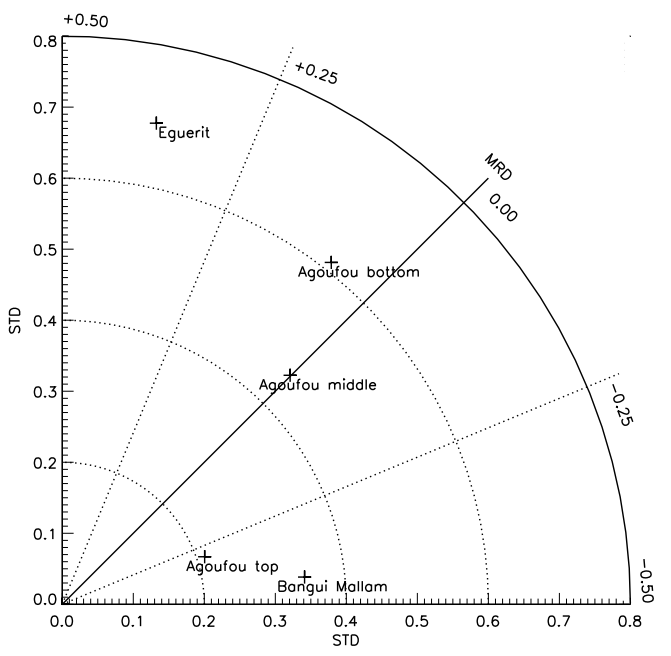

Fig. 9. Mean Relative Difference (MRD) and its time Standard Deviation (STD) (see text, section 5) for the volumetric surface soil moisture of each of the five stations considered at the Agoufou super site scale compared to the site average. 
1 Soil Moisture stations installed at the Gourma meso-scale site. Name and location of each stations are indicated, as well as the depth of measurements and date of installation. Qualitative indication of surface soil texture is indicated for each station, expect for Eguérit which has rocky soil. US Department of Agriculture (USDA) soil texture is given for Agoufou top and bottom of hillslope, where texture measurements were performed (Table 2).

2 Vertical profile of soil texture on the Agoufou local site. Fraction are indicated in per thousand. Particles size are defined according to the USDA classification scheme, with clay $(<0.002 \mathrm{~mm})$, fine silt $(0.002-0.02 \mathrm{~mm})$, coarse silt $(0.02-0.05 \mathrm{~mm})$, fine sand $(0.05-0.2 \mathrm{~mm})$, coarse sand $(0.2-2 \mathrm{~mm})$ (Gee and Bauder 1986).

3 Number of transect measurements performed in 2005 and 2006 on Agoufou and some of the others coarse textured sites.

4 Statistical results of the comparison between the kilometer scale surface soil moisture obtained by up-scaling of local station measurements, $S S M_{s t a 1 k m}$, and transect measurements, $S S M_{\text {tra1km }}$ (see text). For each row a data set is selected corresponding to different sites and different years. The number of observations is indicated by $N$ in the last column. 
Site

Location

Sensors types and depth $(\mathrm{cm})$

date

\begin{tabular}{|c|c|c|c|c|c|c|c|}
\hline Number & Name & Soil Text. & Lat. & Lon. & Soil Moisture & Temperature & \\
\hline $17-\mathrm{P} 1$ & $\begin{array}{l}\text { Agoufou } \\
\text { bottom }\end{array}$ & Sandy-Loam & $15.341^{\circ} \mathrm{N}$ & $1.479^{\circ} \mathrm{W}$ & $\begin{array}{l}7 \mathrm{CS} 616 \\
5,30,60,120,150,250,400\end{array}$ & $\begin{array}{l}4 \mathrm{PT} 108 \\
5,30,60,120\end{array}$ & 04-2005 \\
\hline $17-\mathrm{P} 2$ & middle & Coarse & $15.345^{\circ} \mathrm{N}$ & $1.479^{\circ} \mathrm{W}$ & $6 \mathrm{CS} 616$ & 2 PT108 & 04-2006 \\
\hline $17-\mathrm{P} 3$ & top & Sand & $15.345^{\circ} \mathrm{N}$ & $1.479^{\circ} \mathrm{W}$ & $\begin{array}{l}5,30,60,120,180,250 \\
5 \text { CS616 } \\
5,10,40,120,220\end{array}$ & $\begin{array}{l}5,30 \\
2 \text { PT108 } \\
5,40\end{array}$ & 04-2004 \\
\hline $\mathrm{BB}-\mathrm{P} 5$ & Bamba & Coarse & $17.099^{\circ} \mathrm{N}$ & $1.402^{\circ} \mathrm{W}$ & $\begin{array}{l}6 \mathrm{CS} 616 \\
5,40,80,120,180,250\end{array}$ & $\begin{array}{l}5 \mathrm{PT} 108 \\
5,10,40,80,120\end{array}$ & 04-2004 \\
\hline $4-\mathrm{P} 6$ & In Zaket & Coarse & $16.572^{\circ} \mathrm{N}$ & $1.789^{\circ} \mathrm{W}$ & $\begin{array}{l}7 \text { CS616 } \\
5,10,30,80,120,180,250\end{array}$ & $\begin{array}{l}4 \mathrm{PT} 108 \\
5,10,30,80\end{array}$ & 07-2005 \\
\hline $12-\mathrm{P} 7$ & Ekia & Coarse & $15.965^{\circ} \mathrm{N}$ & $1.253^{\circ} \mathrm{W}$ & $\begin{array}{l}7 \text { CS616 } \\
5,10,30,80,120,180,250\end{array}$ & $\begin{array}{l}4 \mathrm{PT} 108 \\
5,10,30,80\end{array}$ & 06-2005 \\
\hline EM - P8 & $\begin{array}{l}\text { Bangui } \\
\text { Mallam }\end{array}$ & Coarse & $15.398^{\circ} \mathrm{N}$ & $1.345^{\circ} \mathrm{W}$ & $\begin{array}{l}7 \text { CS616 } \\
5,10,30,80,120,180,250\end{array}$ & $\begin{array}{l}4 \mathrm{PT} 108 \\
5,10,30,80\end{array}$ & 04-2005 \\
\hline $20-\mathrm{P} 9$ & Kelma & Fine & $15.218^{\circ} \mathrm{N}$ & $1.566^{\circ} \mathrm{W}$ & $\begin{array}{l}4 \text { Theta-probes } \\
5,20,80,100\end{array}$ & $\begin{array}{l}4 \text { PT108 } \\
5,20,80,100 \\
\end{array}$ & 06-2005 \\
\hline $40-\mathrm{P} 10$ & Eguérit & Rock & $15.503^{\circ} \mathrm{N}$ & $1.392^{\circ} \mathrm{W}$ & $\begin{array}{l}2 \mathrm{CS} 616 \\
10,50\end{array}$ & $\begin{array}{l}4 \text { PT108 } \\
10,50\end{array}$ & 04-2005 \\
\hline $25-\mathrm{P} 11$ & Kinia & Coarse & $15.051^{\circ} \mathrm{N}$ & $1.546^{\circ} \mathrm{W}$ & $\begin{array}{l}7 \mathrm{CS} 616 \\
5,10,30,80,120,180,250\end{array}$ & $\begin{array}{l}4 \mathrm{PT} 108 \\
5,10,30,80\end{array}$ & 03-2007 \\
\hline
\end{tabular}

Table 1

Soil Moisture stations installed at the Gourma meso-scale site. Name and location of each stations are indicated, as well as the depth of measurements and date of installation. Qualitative indication of surface soil texture is indicated for each station, expect for Eguérit which has rocky soil. US Department of Agriculture (USDA) soil texture is given for Agoufou top and bottom of hillslope, where texture measurements were performed (Table 2). 


\begin{tabular}{|c|c|c|c|c|c|}
\hline \multicolumn{6}{|c|}{ Bottom of hillslope } \\
\hline Depth (cm) & Clay & Fine Silt & Coarse Silt & Fine Sand & Coarse Sand \\
\hline 5 & 96 & 89 & 69 & 352 & 394 \\
\hline 10 & 53 & 31 & 28 & 338 & 550 \\
\hline 20 & 68 & 31 & 18 & 348 & 535 \\
\hline 30 & 78 & 32 & 15 & 355 & 520 \\
\hline 40 & 87 & 31 & 19 & 392 & 471 \\
\hline 50 & 82 & 27 & 15 & 377 & 499 \\
\hline 60 & 90 & 26 & 26 & 438 & 420 \\
\hline 70 & 86 & 26 & 11 & 445 & 432 \\
\hline 80 & 90 & 22 & 12 & 505 & 371 \\
\hline 90 & 86 & 18 & 15 & 524 & 357 \\
\hline 100 & 78 & 13 & 19 & 544 & 346 \\
\hline \multicolumn{6}{|c|}{ Top of Hillslope } \\
\hline Depth $(\mathrm{cm})$ & Clay & Fine Silt & Coarse Silt & Fine Sand & Coarse Sand \\
\hline 5 & 34 & 11 & 13 & 385 & 557 \\
\hline 10 & 34 & 14 & 13 & 421 & 518 \\
\hline 20 & 37 & 18 & 6 & 418 & 521 \\
\hline 30 & 44 & 11 & 4 & 431 & 510 \\
\hline 40 & 47 & 8 & 1 & 507 & 437 \\
\hline 50 & 42 & 9 & 3 & 469 & 477 \\
\hline 60 & 40 & 6 & 8 & 448 & 498 \\
\hline 70 & 42 & 2 & 5 & 462 & 489 \\
\hline 80 & 36 & 4 & 4 & 465 & 491 \\
\hline 90 & 33 & 3 & 2 & 453 & 509 \\
\hline 100 & 29 & 11 & 8 & 533 & 419 \\
\hline
\end{tabular}

Vertical profile of soil texture on the Agoufou local site. Fraction are indicated in per thousand. Particles size are defined according to the USDA classification scheme, with clay $(<0.002 \mathrm{~mm})$, fine silt $(0.002-0.02 \mathrm{~mm})$, coarse silt $(0.02-0.05 \mathrm{~mm})$, fine sand (0.05-0.2mm), coarse sand (0.2-2mm) (Gee and Bauder 1986). 


\begin{tabular}{llll} 
Site & 2005 & 2006 & Direction \\
\hline Agoufou & 25 & 9 & West \\
Bangui Mallam & 1 & 7 & South \\
Bamba & 1 & 0 & North \\
Ekia & 1 & 2 & South \\
Agoufou-hydro & 0 & 10 & Topographical \\
\hline Total & 28 & 28 &
\end{tabular}

Table 3

Number of transect measurements performed in 2005 and 2006 on Agoufou and some of the others coarse textured sites. 


\begin{tabular}{ll|llll|l} 
Site & Year & $R M S E(\%)$ & $R$ & EFF & BIAS & $N$ \\
\hline Bangui Mallam & 2006 & 1.6 & $\mathbf{0 . 8 9}$ & 0.8 & $10^{-4}$ & 7 \\
\hline Agoufou & $2005-2006$ & & & & & \\
Top (P3) & & 0.9 & $\mathbf{0 . 9 7}$ & 0.94 & $10^{-4}$ & 34 \\
Bottom (P1) & & 1.9 & $\mathbf{0 . 8 6}$ & 0.73 & $10^{-4}$ & 34 \\
\hline Agoufou & 2006 & & & & & \\
Top (P3) & & 0.97 & $\mathbf{0 . 9 7}$ & 0.94 & $10^{-4}$ & 9 \\
Bottom (P1) & & 1.7 & $\mathbf{0 . 9 1}$ & 0.83 & $10^{-5}$ & 9 \\
Middle (P2) & & 1.4 & $\mathbf{0 . 9 4}$ & 0.88 & $10^{-4}$ & 9 \\
\hline Multi-site & $2005-2006$ & 2.2 & $\mathbf{0 . 8 2}$ & 0.66 & $10^{-4}$ & 21
\end{tabular}

Table 4

Statistical results of the comparison between the kilometer scale surface soil moisture obtained by up-scaling of local station measurements, $S S M_{s t a 1 \mathrm{~km}}$, and transect measurements, $S S M_{t r a 1 k m}$ (see text). For each row a data set is selected corresponding to different sites and different years. The number of observations is indicated by $N$ in the last column. 


\title{
Multi-scale soil moisture measurements at the Gourma meso-scale site in Mali
}

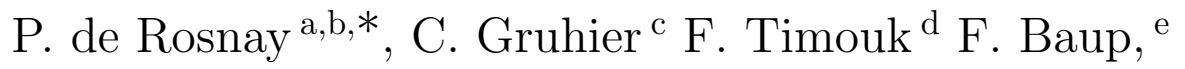

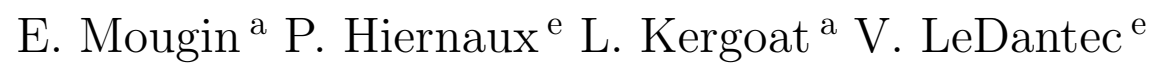 \\ ${ }^{\mathrm{a}}$ CNRS/CESBIO, Toulouse, France \\ ${ }^{\mathrm{b}} E C M W F$, Reading, $U K$ \\ ${ }^{\mathrm{c}}$ CNRS/CNES/CESBIO, Toulouse, France \\ ${ }^{\mathrm{d}}$ IRD/CESBIO, Toulouse, France \\ ${ }^{\mathrm{e}} U P S / C E S B I O$, Toulouse, France
}

\begin{abstract}
This paper presents the ground soil moisture measurements performed over the socalled Gourma meso-scale site in Mali, Sahel, in the context of the African Monsoon Multidisciplinary Analysis (AMMA) project. The Gourma meso-scale soil moisture network is part of a complete land surface processes observing and modelling strategy and is associated to vegetation and meteorological field measurements as well as soil moisture remote sensing. It is spanning $2^{\circ}$ in latitude between $15^{\circ} \mathrm{N}$ and $17^{\circ} \mathrm{N}$. In 2007, it includes 10 soil moisture stations, of which 3 stations also have meteorological and flux measurements. A relevant spatial sampling strategy is proposed to characterise soil moisture at different scales including local, kilometer, super-site and meso-scales. In addition to the local stations network, transect measurements were performed on different coarse textured (sand to sandy-loam) sites, using portable impedance probes. They indicate mean value and standard deviation (STD) of the
\end{abstract}


surface soil moisture (SSM) at the kilometer scale. This paper presents the data set and illustrates soil moisture spatial and temporal features over the Sahelian Gourma meso-scale site for 2005-2006. Up-scaling relation of SSM is investigated from (i) local to kilometer scale and (ii) from local to the super site scale. It is shown to be stable in space and time (2005-2006) for different coarse textured sites. For the Agoufou local site, the up-scaling relation captures SSM dynamics at the kilometer scale with a $0.9 \%$ accuracy in volumetric soil moisture. At the multi-site scale, an unique up-scaling relation is shown to be able to represent kilometer SSM for the coarse textured soils of the meso-scale site with an accuracy of $2.2 \%$ (volumetric). Spatial stability of the ground soil moisture stations network is also addressed by the Mean Relative Difference (MRD) approach for the Agoufou super site where 5 soil moisture stations are available (about $25 \mathrm{~km} \times 25 \mathrm{~km}$ ). This allows the identification of the most representative ground soil moisture station which is shown to be an accurate indicator with low variance and bias of the soil moisture dynamics at the scale of the super site. Intensive local measurements, together with a robust upscaling relation make the Gourma soil moisture network suitable for a large range of applications including remote sensing and land surface modelling at different spatial scales.

Key words: Soil Moisture, ground measurements, up-scaling, Sahel, AMMA

\section{$1 \quad 1 \quad$ Introduction}

2 West Africa, and more specifically the Sahel, is pointed out by Koster et al. (2004)

3 to be one of the regions of the world with the strongest feedback mechanism between

4 soil moisture and precipitation. This hot spot "indicates where the routine monitor-

* Corresponding author: Tel: +44 118949 9625, Fax: +44 1189869450

Email address: Patricia.Rosnay@ecmwf .int (P. de Rosnay). 
5 ing of soil moisture, with both ground-based and space-based systems, will yield the

6 greatest return in boreal summer seasonal forecasting." One of the key objectives of

7 AMMA (African Monsoon Multidisciplinary Analysis) project, is to improve our un-

8 derstanding and our modelling capabilities of the effect of land surface processes on

9 monsoon intensity, variability and predictability (Redelsperger et al. 2006). AMMA

10 is supported by a very strong observational program. Three meso-scale sites are in-

1 strumented in Mali, Niger and Bénin, providing information along the North-South

12 gradient between Sahelian and Soudanian regions (Redelsperger et al. 2006). The

13 instrumental deployment in the Gourma region (the sahelian site of Mali) focuses

14 on quantification of water, CO2 and energy fluxes between the surface and the

15 atmosphere (Mougin et al., this issue). Among the surface processes under con-

16 sideration, emphasis is put on evapotranspiration which is the most important

17 process coupling the physical, biological and hydrological processes at the conti-

18 nental scale. Soil moisture is a crucial variable that affects many processes includ-

19 ing land-surface-atmosphere interactions (Taylor et al. 2007; Taylor and Ellis 2006;

20 Monteny et al. 1997; Nicholson et al. 1997), land surface fluxes (Timouk et al. this

21 issue; Lloyd et al. 1997), vegetation phenology (Seghieri et al. this issue), and soil

22 respiration (Le Dantec et al. 2006). The diversity of processes and the correspond-

23 ing large range of spatial and temporal scales involved in the monsoon dynamics

24 require accurate estimate of soil moisture dynamics at local scale, meso-scale and

25 regional scale. Ground measurements provide vertical soil moisture profiles with a

26 high accuracy but they are limited to the local scale. In contrast, remote sensing ap-

${ }_{27}$ proaches provide spatially integrated measurements of surface soil moisture (SSM)

28 but they are limited to the very first top centimetres of the soil (Kerr 2007). Soil

29 moisture estimation from microwave remote sensing was investigated during the Hy-

so drological and Atmospheric Pilot Experiment in the Sahel (HAPEX-SAHEL), using

31 both passive microwave radiometry from airborne measurements (Schmugge 1998;

32 Chanzy et al. 1997; Calvet et al. 1996) and active microwave remote sensing with 
ERS satellite data (Magagi and Kerr 1997). These studies were based on local soil moisture ground measurements acquired for a few month during the 1992 summer campaign. Extensive field measurement campaigns have been conducted in other regions of the Earth to characterise the soil moisture variability, as for example in the U.S. Midwest, South Central Georgia and Southern Great Plains (SGP) (De Lannoy et al. 2007; Bosch et al. 2006; Famiglietti et al. 1999), and in Australia (Rüdiger et al. 2007). Using airborne based remote sensing information, Kim and Barros (2002) examined the statistical structure of soil moisture $(40 \times 250 \mathrm{~km})$ obtained during the SGP 1997 hydrology experiment. In Sahel, where field instrumentation and extensive field campaigns are more difficult, extensive soil moisture measurements were not available until now. In the framework of AMMA the Gourma meso-scale site has been instrumented for soil moisture measurements. It is described in this paper.

For the purpose of satellite validation it is of crucial importance to address up-scaling issues of ground soil moisture measurements. Baup et al. (2007) used ground soil moisture measurements over the Agoufou local site, in Mali, for the purpose of ENVISAT/ASAR soil moisture inversion. To this end they used surface soil moisture measurements from one local station, up-scaled to the $1 \mathrm{~km}$ remotely sensed pixel for 2005. In the present paper, surface soil moisture up-scaling of ground measurements is investigated at the single site scale and extended to (i) the multi-site spatial scale, within the Gourma meso-scale windows, and (ii) the inter-annual temporal scale. A complementary approach, suitable for larger scale applications, consists of deriving spatially representative soil moisture estimates from ground observation networks. The method, first proposed by Vachaud et al. (1985), is based on the Mean Relative Difference (MRD) and deviation between stations of the same network. It was applied by Cosh et al.(2004) to the Soil Moisture EXperiment (SMEX) 2002 (Jackson et al. 2003) for the validation of the Advanced Microwave Scanning Radiometer on Earth Observing System (AMSR-E) soil moisture. De Lannoy et al. 
(2007) used the MRD approach combined with cumulative distribution function matching to estimate the spatial mean soil moisture. Based on the MRD, Gruhier et al. (2008) used the Gourma meso-scale soil moisture measurements to validate the soil moisture products obtained for 2005 from AMSR-E.

Ground soil moisture measurements are also highly relevant to validate Land Surface Models (LSMs). As for satellite validation, up-scaling is crucial to characterise soil moisture at the scale of the LSM. In turn, land surface models allow for the extension of local scale measurements to larger spatial scales. This is being addressed over West Africa through the AMMA Land Surface Model Intercomparison Project (ALMIP, Boone et al. 2008).

The main purpose of this paper is to describe the Gourma meso-scale soil moisture network and to presents soil moisture measurements for 2005-2006. Based on local and transect measurements and using the Mean Relative Difference method, this paper also presents some features of the soil moisture characteristics and investigates the potential of the Gourma soil moisture measurements to address surface soil moisture up-scaling. Next section describes the Gourma meso-scale soil moisture network. Section 3 presents the soil moisture dynamics for different stations along the $15^{\circ} \mathrm{N}$ to $17^{\circ} \mathrm{N}$ climatic gradient for 2005 and 2006. Section 4 focuses on surface soil moisture up-scaling. Representativity of ground soil moisture station is addressed in section 5 for the Agoufou super site, where the Mean Relative Difference approach is applied to the Gourma soil moisture network. Section 6 concludes. 


\section{Experimental design and ground soil moisture measurements}

\subsection{The Mali site}

The AMMA project aims at providing a better understanding of the African monsoon processes. AMMA relies on an extensive field campaign experiment for which three meso-scale sites are instrumented in Bénin, Niger and Mali (Redelsperger et al. 2006).

Instrumental deployment over the Mali site includes three monitoring scales described hereafter (Mougin et. al, this issue).

- The Gourma meso-scale site $\left(30,000 \mathrm{~km}^{2}, 14.5^{\circ} \mathrm{N}-17.5^{\circ} \mathrm{N} ; 1^{\circ} \mathrm{W}-2^{\circ} \mathrm{W}\right)$ is shown in Figure 1. The location of the soil moisture stations (10 stations) is indicated on the map by white stars. Each soil moisture station also includes a rain-gauge for rainfall measurements and three stations (in Bamba, Eguérit, Agoufou) include complete weather station and flux measurements. More detail on rainfall measurements over Gourma are provided in Frappart et al. (this issue), while Lebel and Ali (this issue) investigate the rainfall regime fluctuations in Sahel. The Gourma meso-scale site is characterised by a Sahelian to saharo-sahelian climate (isohyets 500-100 mm). Soil is coarse textured (sand, loamy sand, sandy loam) for $65 \%$ of the area, where vegetation is composed of a layer of natural annual herbs with scattered trees and shrubs (Hiernaux et al. this issue). $28 \%$ of the meso-scale site is characterised by flat and shallow soils and rock outcrops (loamy colluvium, schist, sandstone outcrops and hard pan). Vegetation on these rocky-loam areas consists of scattered shrubs. The remaining $7 \%$ of the area are clay plains, temporarily flooded woodlands and flooded depressions. Data on herbs and woody vegetation are collected on 43 local sites among which some are also used for validation of remote sensing products (LAI, Net Primary Productivity, soil moisture) derived form SPOT-VGT, MODIS, AMSR-E, ENVISAT/ASAR, ERS (Gruhier 
- The Agoufou super site $\left(2,250 \mathrm{~km}^{2}, 15.3^{\circ} \mathrm{N}-15.58^{\circ} \mathrm{N} ; 1.38^{\circ} \mathrm{W}-1.65^{\circ} \mathrm{W}\right)$ is shown in Figure 1 (right). At this scale, ground measurements focus on land surface fluxes measurements as well as on spatial heterogeneities of fluxes and vegetation characteristics.

- The Agoufou local intensive site $\left(1 \mathrm{~km}^{2}, 15.3^{\circ} \mathrm{N} ; 1.3^{\circ} \mathrm{W}\right)$ is indicated on Figure 1. Annual mean precipitation is $370 \mathrm{~mm}$ (1920-2003). The site has measurements of vegetation, soil moisture, meteorology and land surface fluxes (energy, water, CO2). The data collected on this site are used to parameterise, test and validate LSMs. The Agoufou local site is also a main validation site for remote sensing products.

\subsection{Ground soil moisture measurements}

The colours in Figure 1, obtained from a Landsat image, indicate the surface types on which the stations are deployed, with green for gently undulating coarse textured dune systems, dark green for clay soil types and brown-pink for flat rockyloam plains. Table 1 provides detailed information concerning soil moisture stations (number, name, soil type, location, sensors types and depth, date of installation). The same installation protocol is used for all the soil moisture stations, where Time Domain Reflectometry sensors are used (Campbell CS616), except for the Kelma station. For the later, Delta-T Theta Probe sensors are used since they are equipped with short rods which is more suitable for clay soils (a mention of the manufacturers is for information only and implies no endorsement on the part of the authors). The Gourma soil moisture stations all include a first measurement at $5 \mathrm{~cm}$ depth, except in Eguérit (rocky) where the first measurement is at $10 \mathrm{~cm}$ depth. Soil moisture profiles are measured down to $50 \mathrm{~cm}$ depth for Eguérit, and down to $4 \mathrm{~m}$ for Agoufou 
at the bottom of a hillslope. In order to capture the fast soil moisture dynamics, the vertical resolution of automatic soil moisture measurements in the soil is very fine at the surface, and measurements are acquired at 15 minutes time intervals. For remote sensing and land surface modelling purpose, both soil moisture and soil temperature profiles are monitored. For each station and each sensor depth, calibration was performed, based on local soil density and gravimetric soil moisture measurements. Gravimetric measurements were performed at different stages of the rainy season to ensure calibration robustness in various soil moisture conditions. Soil moisture values provided in this paper are expressed in terms of volumetric units.

Soil texture measurements were performed for the first meter of soil, in the Agoufou local intensive site at the top and bottom of a hillslope (Table 2). Soil texture of the top $10 \mathrm{~cm}$ of soil is slightly different between the top and bottom of the hillslope, with silt and clay content higher at the bottom than at the top of the hillslope. However the soil is very coarse textured, with more than $74 \%$ and $94 \%$ of sand particles at surface for the bottom and top of the hillslope respectively.

The Gourma soil moisture network documents soil moisture dynamics along the North-South climatic gradient, as well as at the dune scale, with three stations located on the Agoufou local site at different levels of a typical hillslope (top, middle and bottom). Eight stations are located on coarse textured soils (sandy to sandyloam) which represents $65 \%$ of the meso-scale site area. One station, in Kelma (site 21 ) is implemented on a clay soil, covered by acacia forest, representing $7 \%$ of the meso-scale area, and one station is located in Eguérit, on a rocky surface that represents $28 \%$ of the area.

In addition to the local stations network, transect measurements have been manually performed every year since 2004 during the rainy season. They consist in monitoring surface soil moisture $(0-5 \mathrm{~cm})$ by the means of a portable impedance probe (Theta probe) every $10 \mathrm{~m}$ along a $1 \mathrm{~km}$ straight transect. The location of each 
point measurement along the transect is chosen to be different (separated by a few centimetres) from one transect date to another. This ensures avoiding soil disturbances that would affect the soil moisture measurements. This method allows estimating, for each transect measurement, both the mean value and standard deviation of the surface soil moisture along the $1 \mathrm{~km}$ transect. For practical reasons it is not possible to perform transect measurements on rocky surfaces (too hard to use the probe), nor in flooded plains (under water). Thus transect measurements have been performed on coarse textured soils, which represent the dominant soil texture type at meso-scale. Intensive transect measurements campaigns were performed on the Agoufou local site where soil moisture is the most intensively documented. For this site the $1 \mathrm{~km}$ transect is the same as that used for vegetation measurements (Hiernaux et al. this issue). It is located on the Agoufou site with the starting and closest point located about $100 \mathrm{~m}$ from the Agoufou bottom of the hillslope station (P1) and about 300m from the top of hillslope (P3) and middle of hillslope (P2) stations. In 2005 and 2006, transect measurements were also extended to the other coarse textured sites of Bangui Mallam, Ekia and Bamba. For these 3 sites, the $1 \mathrm{~km}$ transects start exactly from the soil moisture stations. The $1 \mathrm{~km}$ transects aim to provide information on mean surface soil moisture at the kilometer scale. These measurements are not combined with topography measurements. In 2006 an additional transect was defined on the Agoufou local intensive site for the purpose of hydrological applications and vegetation monitoring in relation to soil moisture along a topographic profile. SSM measurements performed along the hydrological transect are combined with elevation measurements. In contrast to the $1 \mathrm{~km}$ transects, this hydrological transect is not straight. It is $1255 \mathrm{~m}$ long and cuts across 7 catchments located partly within the Agoufou intensive site. It starts from the top of hillslope (P3) station, passes on the bottom of hillslope station (P1) and it is at a distance of about $100 \mathrm{~m}$ from the middle of hillslope station (P2). Table 3 indicates the number of transect measurements performed on each site for these two years. 
Remote sites, more difficult to access, are less documented, as in Bamba where only 1 transect measurement was performed.

[Table 1 about here.]

[Table 2 about here.]

[Table 3 about here.]

[Fig. 1 about here.]

\section{Soil Moisture Dynamics over the Gourma meso-scale site}

\subsection{Temporal dynamics}

Inter-annual variability between 2005 and 2006 is shown in Figure 2 for the surface (5cm depth) soil moisture monitored for eight stations located along the north-south gradient and for different soil types. The horizontal axis indicates the Day of Year (DoY). Note that the vertical axis is identical for each station except Kelma (P9, bottom right). Kinia (P11) and Agoufou middle (P2) are not presented since the data set is not complete for the considered period. In the In Zaket station, the 2005 data set is limited to DoY 198-228, which provides one month of data between the station installation in July and its theft in August. The 2006 data set is complete after the station was reinstalled. Data are missing for Eguérit in early 2006 for technical reasons. So inter-annual variability in monsoon onset is not visible for these two last stations.

The top panel shows SSM of the most northern stations in Bamba and In Zaket. They both present similar features in their surface soil moisture dynamics which is relatively slow and low amplitude. The second panel shows the surface soil mois- 
ture dynamics for Ekia and Bangui Mallam and the third panel presents surface soil moisture for two stations located in the Agoufou super site at the top and bottom of the hillslope. Surface soil moisture is characterised by higher values and a larger temporal variability on these sites than on the northern sites. The bottom panel shows the surface soil moisture evolution for the two non-sandy sites of the Gourma soil moisture network, located in Eguérit (rocky) and in Kelma (clay). They both show a lower temporal variability in surface soil moisture. The Kelma site is characterised by much higher soil moisture values, due to the clay soil texture in this area. In addition, this site is flooded during the rainy season as indicated by the maximum soil moisture values maintained at saturation for more than one month during the monsoon season. For the top three panels, which present surface soil moisture monitored on coarse textured sites, differences between the sites are mainly governed by the strong North-South climatic gradient and by the precipitation variability. In contrast, for the bottom panel, the distances between the sites is less (all sites are within the super site) and the precipitation variability between the sites is lower. Accordingly, differences in soil moisture dynamics are mainly governed for these sites by differences in surface properties (soil texture and vegetation cover) and subsequent land surface processes (partitioning between evapotranspiration and runoff).

For coarse textured soils the infiltration rate is very high according to the large amount of sand particles (higher than 74\%). Surface ponding occurs rarely on these soils and it is located in very specific and limited areas (a few square meters) for very short periods (a few hours after rain). None of the soil moisture stations installed on coarse textured soils are affected by ponding. Despite temporal dynamics and absolute values of soil moisture being different between stations depending on both surface properties and location along the climatic transect, all the stations capture the later monsoon onset in 2006 than in 2005 that was described by Janicot et al. (2008). 


\subsection{Vertical dynamics}

Figure 3 (top) depicts the temporal evolution of soil moisture at different depths at the Bangui Mallam station during the 2006 summer. It clearly shows that soil moisture dynamics is very fast at the surface, with rapid soil moisture response to precipitation occurrence, and fast soil drying afterwards. Soil moisture dynamics is getting slower with increasing depth, and at $120 \mathrm{~cm}, 180 \mathrm{~cm}$ and $250 \mathrm{~cm}$ depth, soil moisture shows variability mainly at the seasonal time scale.

A major rainfall event (61.5mm at this station) occurred in the early morning of the DoY 210. It was associated with a large convective system that gave precipitation from Kelma to Ekia (Figure 1), as can be seen on Figure 2 with the surface soil moisture increasing on DoY 210 in 2006 for the 6 stations concerned. This event is chosen here to illustrate the vertical soil moisture dynamics at the Bangui Mallam site which is representative of vertical dynamics of coarse textured sites of the Gourma region.

Figure 3 (middle) shows the vertical structure of soil moisture evolution of the Bangui Mallam station at four different dates around this precipitation event, between July 28 (DoY 209) and August 2 (DoY 214) 2006. Figure 3 (bottom) shows the water budget as estimated from ground observations of soil moisture and precipitation for this period for the Bangui Mallam site. In particular it indicates the accumulated precipitation since DoY 209, and the variation in total soil water content (W) for the $0-1 \mathrm{~m}$ soil layer and for the $1-2 \mathrm{~m}$ soil layer (dW $0-1 \mathrm{~m}$ and $\mathrm{dW} 1-2 \mathrm{~m}$ respectively). Vertically integrated soil water content is computed for each time step by the means of a linear vertical interpolation and integration of volumetric soil moisture profiles. Accordingly it must be taken with caution due to uncertainties associated to the vertical profiles. This is particularly the case for the second meter of soil where the 
vertical sampling of soil sensors is more sparse (Table 1). After a rainfall event, the presence of a wetting front, associated to a discontinuity in the soil moisture profile, is also expected to affect the accuracy of the vertical interpolation. Despite of these uncertainties, when considering its temporal evolution, the vertically integrated water content provides an estimate of the time evolution of the soil water budget.

Soil moisture profiles shown in Figure 3 (middle) indicate very dry conditions (volumetric soil moisture below 2\% ) on DoY 209 at all soil depths at the Bangui Mallam station. The strong precipitation event that occurred on DoY 210 led to a fast response of soil moisture in the first half meter of soil, with an increase to $12.5 \%$ (volumetric) at $10 \mathrm{~cm}$ depth. However the wetting front didn't reach yet the $80 \mathrm{~cm}$ deep soil moisture sensor for which the volumetric soil moisture was steady bellow $2 \%$. The vertical profile depicted for DoY 211 shows that 1.5 days after the rain occurred, the wetting front got deeper, down to $80 \mathrm{~cm}$, while the first $30 \mathrm{~cm}$ of soil already started to dry out. A few days later (DoY 214) while 2 rainfall events occurred (21.5mm each) in the morning and evening of the DoY 212, the vertical profile of soil moisture shows that the wetting front reached $120 \mathrm{~cm}$ depth. Figure 3 (bottom) shows that the cumulated rainfall between DoY 209 and 214 is $104 \mathrm{~mm}$. The total soil water increase $(\mathrm{dW} 0-1 \mathrm{~m}+\mathrm{dW} 1-2 \mathrm{~m})$ for this period is $85.3 \mathrm{~mm}$. The lower value of total soil water increase compared to accumulated precipitation, is explained by several processes, including direct soil evaporation, water uptake for plant transpiration and surface runoff. It is interesting to note that, for each of the three rainfall events, the $0-1 \mathrm{~m}$ soil water content decreased rapidly as soon as the rain stopped. It is due to direct soil evaporation and strong rates of plant transpiration. In addition, the downward propagation of the wetting front, when it reached the $1-2 \mathrm{~m}$ soil layer, strongly contributed to the $0-1 \mathrm{~m}$ layer drying after DoY 213 (2.75 day after the first rainfall event). At the same time, dW1-2m started to strongly increase accordingly on DoY 213, due to deep soil infiltration from the first meter to the second meter of soil. 


\section{Surface soil moisture up-scaling}

Results of transect measurements are presented in this section. The local to kilometer up-scaling relation is investigated at the single-site scale, considering annual and inter-annual temporal scales, as well as at the multi-site scale. As described in section 2 and Table 3, transect measurements were performed in 2005 and 2006 during intensive field campaign measurements conducted during the monsoon season.

\subsection{Bangui Mallam site}

Figure 4 illustrates the surface soil moisture variability along the Bangui Mallam $1 \mathrm{~km}$ transect, for which measurements were performed at different dates between 11 and 16 August 2006. A strong precipitation event occurred on August 9 (DoY 221), 2 days before the first transect measurement, followed by a long drying period. This figure illustrates the strong spatial variability along the transect. However, values of standard deviation (STD) indicated on the figure for the three dates, also show that surface soil moisture spatial variability decreases when soil is drying. The relationship between the soil moisture mean value and its spatial variability is investigated further in section 4.3 at the multi-site scale. Figure 4 also shows the very fast temporal dynamics associated with the soil drying after a precipitation event. In five days, volumetric surface soil moisture drops from $10.8 \%$ to $1.0 \%$. This fast drying of the soil surface is due to fast infiltration rates of coarse textured soils and large evaporation rates. 
Based on transect measurements and local station measurements at Bangui Mallam acquired at the same time, a relationship is established between the averaged $1 \mathrm{~km}$ transect surface soil moisture $\left(S S M_{\text {tra1km }}\right)$ and the local station surface soil moisture $\left(S S M_{\text {staloc }}\right)$ for the Bangui Mallam site in 2006:

$$
S S M_{\text {tra } 1 \mathrm{~km}}=-2.2365+1.5458 \times S S M_{\text {staloc }}
$$

where both $S S M_{\text {tra1km }}$ and $S S M_{\text {staloc }}$ are in \% (volumetric). The slope larger than 1 (1.5458) indicates slightly stronger surface soil moisture changes on the transect compared to the local station. This is explained by the difference of sensing depth between the local station and transect measurements. The top few centimetres of the soil are characterised by very strong soil moisture (and soil temperature) gradients. The very surface soil moisture, which is more directly exposed to the atmosphere, depicts slightly larger variations than at $5 \mathrm{~cm}$ depth, where the variations are already slightly attenuated. Thus the time evolution of the surface soil moisture is sensitive to the depth of measurement. This issue has important implications for remote sensing applications which measure about the top $1 \mathrm{~cm}, 2 \mathrm{~cm}$ and $5 \mathrm{~cm}$ soil moisture at X-band, C-band and L-band respectively, as indicated by Le Morvan et al. 2008 and Jackson et al., 1997. In our study the first sensor of the station is horizontally placed at $5 \mathrm{~cm}$ depth, whereas the transect measurements measure the averaged value between 0 and $5 \mathrm{~cm}$ deep. Shallower measurements lead to slightly larger soil moisture variations along the transects than at the station. This is expressed by a slope larger than one between transect and station measurements. This relationship applied to the station surface soil moisture measurements, allows extrapolating to the kilometer scale, for which $S S M_{s t a 1 k m}$ will be used. Table 4 (first line) shows the statistical results of the comparison between the kilometer surface 
soil moisture obtained from extrapolated station measurements $\left(S S M_{s t a 1 \mathrm{~km}}\right)$ and from the transect measurements $\left(S S M_{t r a 1 k m}\right)$. Comparison is based on several indicators including Root Mean Square Error $(R M S E)$, correlation coefficient $(R)$, Efficiency (Nash coefficient, EFF) and BIAS. Although only seven transects are considered to determine this relation for the Bangui Mallam site in 2006, the very good agreement between the station and the transect measurements $(R=0.89$, $\left.R M S E=1.6 \%, E F F=0.8, B I A S=10^{-4}\right)$, indicates that the up-scaling relation provided in equation 1 is highly suitable to extrapolate from local station measurements at the Bangui Mallam site, to the kilometer scale. Since the station operates automatically, this approach is suitable to derive the kilometer scale surface soil moisture continuously at a fine temporal resolution (15 minute time step). These statistics are obtained when the complete transect data are used. They include 100 measurements for each transect (1 measurement every $10 \mathrm{~m})$. The sensitivity of the correlation to the spatial sampling along the transect is relatively low (not shown). For this site the correlation values stay in the range of 0.87 when measurements are taken every $200 \mathrm{~m}$ (only 5 measurements), to 0.92 when measurements are taken every $80 \mathrm{~m}$ (13 measurements). The stability of the temporal correlation for different spatial sampling distances indicates that the surface soil moisture temporal variability is rather homogeneous along the transect. This explains the robustness of the kilometer scale up-scaling relation.

\subsection{Up-scaling relation for the Agoufou site}

Measurements performed in 2005 and 2006 on the Agoufou site are used here to investigate the inter-annual stability of the up-scaling relationship between surface soil moisture at the local station scale and at the kilometer scale. As indicated in Table 3, 34 1km-transect observations were made for this period on the Agoufou site. The transects cover a wide range of soil moisture conditions. The Agoufou 
site includes 3 soil moisture stations, of which the data from two stations (top and bottom) are available for the whole 2005-2006 period (Table 1). The up-scaling relationship between local and kilometer surface soil moisture is computed and indicated below for theses two stations.

For the Agoufou top of hillslope station:

$$
S S M_{\text {tra } 1 \mathrm{~km}}=-0.68855+1.7561 \times S S M_{\text {staloc }}
$$

For the Agoufou bottom of hillslope station:

$$
S S M_{\text {tra } 1 \mathrm{~km}}=-5.272+1.1812 \times S S M_{\text {staloc }}
$$

Lower slope and intercept parameters are obtained for the bottom of hillslope station than for the top of hillslope one. As expected, this is due to generally higher values of soil moisture content at the bottom than at the top of hillslope. These two relations are applied to the data continuously monitored by the stations in order to estimate the kilometer scale surface soil moisture. Figure 5 shows the scatter-plot of the comparison of the kilometer scale surface soil moisture between station and transect. Statistical results are indicated in Table 4 for Agoufou 2005-2006. Bottom of hillslope up-scaled soil moisture shows a slightly non-linear behaviour related to a pronounced saturation effect for high values of soil moisture.

[Fig. 5 about here.]

[Table 4 about here.]

For this two-year period, best results are obtained with the top of hillslope station, for which the up-scaling relation matches the transect measurements with an accuracy better than $1 \%$ (volumetric), and a correlation coefficient of $R=0.97$. Values of efficiency are also very high for both stations with 0.94 and 0.73 for the top and 
413 be:

bottom station respectively. These statistical results indicate that the up-scaling relation between local surface soil moisture and averaged surface soil moisture along the $1 \mathrm{~km}$ transect is very stable at the inter-annual scale.

Further analysis is conducted to compare surface soil moisture up-scaling performances from the three stations of the Agoufou site, which was only possible for 2006. Statistical results are shown in Table 4. The top of hillslope station (P3) is shown to be the most suitable to up-scale surface soil moisture to the kilometer scale.

\subsection{Multi-site up-scaling relation}

The spatial stability of the $1 \mathrm{~km}$ up-scaling relation is addressed here at the multisite scale. The $1 \mathrm{~km}$ transects acquired on the Agoufou site and on the other coarse textured sites are considered for this study. Since much more measurements were acquired on Agoufou, only the year 2006 is considered for this site, while 2005 and 2006 are considered for the other sites. According to the inter-annual robustness of the surface soil moisture up-scaling relation on Agoufou, eliminating 2005 data for Agoufou does not introduce any bias in the selected data set. It also equilibrates the number of transect measurements between Agoufou and the other sites. Accordingly, 21 transect measurements are available, of which 9 for Agoufou and 12 for the other sites (Table 3). For each transect, the temporally collocated surface soil moisture of the station of the considered site is compared to the transect value. Based on the 21 transects defined above, the multi-site $1 \mathrm{~km}$ up-scaling relation is determined to

$$
S S M_{\text {tra } 1 k m}=-0.52332+1.2995 \times S S M_{\text {staloc }}
$$

Figure 6 (left panel) shows the correspondence between the kilometer scale volumetric surface soil moisture measured from transect measurements and the volumetric 
the soil moisture extrapolated from corresponding local stations. Statistical results are presented in Table 4 . Although the dispersion $(R M S E=2.2 \%)$ is larger than that obtained at the single-site scale for the Agoufou and Bangui Mallam sites ( $0.9 \%$ and $1.6 \%$ respectively), high correlation value $(R=0.82)$ and high efficiency $(E F F=0.66)$ clearly show good skill of this up-scaling relation to describe the $1 \mathrm{~km}$ volumetric surface soil moisture on the different coarse textured sites of the Gourma region. The robustness of the up-scaling relation at the multi-site scale indicates that surface soil moisture scaling characteristics are similar on the different coarse textured sites considered at meso-scale.

As mentioned above for the Bangui Mallam site (Figure 4), higher values of surface soil moisture are associated to higher values of absolute surface soil moisture variability. This relation between surface soil moisture and its spatial variability is investigated at the multi-site scale in Figure 6 (right panel). With a correlation of $R=0.82$, it is shown to be representative at the meso-scale, where all coarse textured sites are considered.

[Fig. 6 about here.]

The multi-site results presented above indicate that (i) the up-scaling relation given in equation 4 describes the $1 \mathrm{~km}$ scale volumetric surface soil moisture from any station of the meso-scale site with an averaged accuracy of $2.2 \%$, and that (ii) characteristics of surface soil moisture variability are similar for the different sites of the meso-scale window, with a $R=0.82$ correlation obtained between surface soil moisture and its spatial variability at $1 \mathrm{~km}$.

This underlines the high degree of representativity of the soil moisture stations for the kilometer scale. The result also suggests highly robust scaling relation of surface soil moisture. It justifies the approach to use a unique multi-site relation for extrapolating kilometer scale soil moisture for each coarse textured site equipped with a soil moisture station. The stability of these relationships across period longer 
than 2 years needs to be confirmed for future up-scaling applications. But for the considered years 2005 and 2006 this data set is shown to be suitable to validate of satellite products with ground station measurements (Gruhier et al. 2008; Zribi et al. this issue; Baup et al. 2008).

\subsection{Hydrological transect over the Agoufou site}

In addition to the $1 \mathrm{~km}$ transect performed on different sites, an hydrological transect was defined. This transect cuts across 7 catchments located within and next to the Agoufou local site. It is $1255 \mathrm{~m}$ long and not straight in order to follow the landscape features. Measurements of surface soil moisture (every 10m) along this transect was repeated 10 times in 2006 as indicated in Table 3. The elevation was assessed by means of a Global Positioning System, so that surface soil moisture variations are monitored in relation with topography information. Figure 7 shows surface soil moisture monitored along this transect at 4 different dates, just after rain on 19 August 2006 am and pm, and a few days before, on August 13 and 15 where no rainfall occurrence led to drying conditions. Topography (elevation in $\mathrm{m}$ ) is indicated on the bottom panel.

[Fig. 7 about here.]

Hydrological transect measurements aim at studying hydrological processes at different levels of the hillslope. Although they are limited to surface soil moisture, they provide complementary information compared to the three local stations of Agoufou which provide a complete vertical profile. Figure 7 qualitatively shows the influence of topography on the surface soil moisture value. In particular, persistent higher soil moisture values are observed near 500m, $875 \mathrm{~m}, 1200 \mathrm{~m}$ which all correspond to low elevation areas. At $1200 \mathrm{~m}$ there is a relative elevation minimum. It is not very pronounced in the direction of the transect but more important in the orthogonal 
direction. This explains the maximum soil moisture at this location. The correlation values, $\mathrm{R}$, between the SSM and the elevation are provided in the figure. They show that the surface soil moisture profile along the transect is negatively correlated to the elevation. This indicates that relatively wet condition are encountered in low elevation areas, while soil is getting dryer when elevation increases. These significant negative correlation values also indicate limited precipitation heterogeneities along the transect. The negative correlation is stronger for wet conditions than for dry conditions. This shows that for wet conditions the soil water distribution along the transect is largely related to the soil topography. For dryer soils the negative correlation is less strong which indicates that other processes, such as evapotranspiration or slight variations in soil texture, also influence the spatial distribution of surface soil moisture. However negative correlation values persist for a large range of soil moisture conditions from very wet (19 August am, a few hours after precipitation) to very dry conditions (15 August, after 10 days without rain).

Figure 8 displays the amplitude of the Discrete Fourier Transform (DFT) of the surface soil moisture and the soil elevation along the hydrological transect. The DFT represents the partitioning of the sample variance into spatial frequency components (Greminger et al., 1985). In Figure 8 DFTs are obtained with a Hamming window. They are represented on a logarithmic scale and expressed in terms of spatial period. The soil moisture DFTs are provided for 3 of the 4 cases considered in Figure 7, which allow the consideration of different soil moisture conditions. For the clarity of the figure the spectrum for the intermediate case of August 19pm is not shown. Process scales occur at spectral peaks, whereas spectral gaps represent spatial scales with minimum spectral variance. The dominant spectral peaks shown for the soil elevation are dominated by long wavelengths (spatial period larger than 100m). The dominant periods are the transect length, $250 \mathrm{~m}$ (extending from $180 \mathrm{~m}$ to $300 \mathrm{~m}$ ) and $100 \mathrm{~m}$. The variability of soil moisture at long wavelength is in relatively good agreement with that of soil elevation. For wet conditions, significant peaks are shown for 
periods of $100 \mathrm{~m}$ and $200 \mathrm{~m}$ in agreement with the soil elevation variability. For dryer soil conditions (Aug. 15), these two peaks are still characterising the soil moisture variability but their amplitude and spatial extention are reduced.

[Fig. 8 about here.]

Much less agreement between topography and soil moisture is shown for short spatial periods (below $80 \mathrm{~m}$ ). This indicates that surface soil moisture variations at smaller spatial scales are less related to the topography than larger scale variations. It is also clear from Figure 8 that smaller scale surface soil moisture variations are of lower amplitude than variations at larger scale.

\section{Temporal stability of the Gourma soil moisture network}

In this section the representativity of the ground soil moisture station is investigated further by the means of Mean Relative Difference method. Built on the Vachaud et al. (1985) approach, $M R D_{i}$ is computed for each station $i$, as:

$$
M R D_{i}=\frac{1}{t} \sum_{j=1}^{t} \frac{S S M_{i, j}-\overline{S S M_{j}}}{\overline{S S M_{j}}}
$$

where $j$ is the time step, $t$ is the number of time steps, $S S M_{i, j}$ is the surface soil moisture of station $i$ at the time step $j, \overline{S S M_{j}}$ is the surface soil moisture averaged over the different stations at the time step $j$. The value of $M R D_{i}$ quantifies the agreement of SSM between station $i$ and the stations average. Its temporal standard deviation $S T D_{i}$, computed from $\left(S S M_{i, j}-\overline{S S M_{j}}\right) /\left(\overline{S S M_{j}}\right)$ time series, quantifies the agreement of surface soil moisture between the local station $i$ and the stations average in term of temporal variability.

This method is applied for the whole year 2006, to the Agoufou super site (Figure 1, right): the three stations of Agoufou are considered together with those of Bangui 
Mallam and Eguérit. These 5 stations encompass an area of about $25 \mathrm{~km} \times 25 \mathrm{~km}$, with soil surface types representative of $90 \%$ of the Gourma meso-scale site. Soil moisture data from each station are weighted according to the soil type distribution over the super site.

[Fig. 9 about here.]

Results of the MRD analysis on the Gourma super site are plotted in Figure 9 on a circle plot where the angle deviation from $45^{\circ}$ gives the MRD value of each station and the radius indicates its standard deviation (STD). This figure clearly shows that the Agoufou middle of hillslope station, for which the MRD value is close to zero, captures almost perfectly the mean annual value of the super site averaged surface soil moisture. Lower values of MRD for the stations located at the top of the hillslope in Agoufou and in Bangui Mallam indicate that these sites are generally dryer than the super site average. In contrast Eguérit and Agoufou Bottom have higher values of their surface soil moisture MRD which indicate that they are wetter than the super site average. These results are in agreement with the qualitative features shown in Figure 2.

Beside its absolute value, surface soil moisture temporal variability is of highest importance. Standard deviation of MRD indicates for each station its representativity at the super site scale in terms of soil moisture temporal variability. The Agoufou top of hillslope station is shown to have the lowest STD (0.21), which shows that is in best agreement with SSM variability at the super site scale. The Bangui Mallam STD is 0.28 , showing this site provides a good estimate of SSM variability as well. STD values of the three other stations are much higher with more than 0.4 for Agoufou middle of hillslope, more than 0.6 for Agoufou bottom of hillslope and almost 0.7 for Eguérit. This indicates that, although surface soil moisture is lowbiased for two of these stations, its temporal variability does not match with that 
observed at the super site scale.

The Agoufou top of hillslope station, with lowest STD and reasonable MRD, is the most representative station of the surface soil moisture at the Agoufou super site scale. This is in agreement with the up-scaling analysis conducted in the previous section at the kilometer scale where the same station is shown to be representative of the kilometer scale SSM through a linear regression.

\section{Conclusion}

This paper presents the Gourma (Mali) meso-scale soil moisture network which has been implemented in the framework of the AMMA project. This soil moisture network is a component of the AMMA's multidisciplinary and multi-scale observing system (Redelsperger et al. 2006). Initially implemented in the context of the Enhanced Observing Period (EOP, 2005-2007), it has been extended to the Long term Observing Period (LOP, 2005-2009) of AMMA.

The Gourma soil moisture network aims at documenting soil moisture dynamics in the sahelian region of Mali, for a large range of temporal and spatial scales at which land surface processes and surface-atmosphere interaction occur. To this end a set of 10 soil moisture stations is spanning $2^{\circ}$ between $15^{\circ} \mathrm{N}$ and $17^{\circ} \mathrm{N}$. Different types of soil surfaces are instrumented according to their spatial distribution over the meso-scale site. Observing results from the 2005-2006 period are presented in this paper.

Soil moisture measurements on coarse textured sites, which represent $65 \%$ of the meso-scale area, clearly show that the temporal surface soil moisture dynamics is highly influenced by the climatic condition and the rainfall variability along the North-South transect (section 3). Northern stations of Bamba and In Zaket are characterised by lower soil moisture values and lower time variability, while stations located within the super site depict higher soil moisture values and variability. Soil 
moisture dynamics is also strongly influenced by surface properties (soil and vegetation types, topography). Flat rocky-loam surfaces, which represent $28 \%$ of the meso-scale site are shown to be characterised by a relatively slow temporal variability. Clay area, covered by acacia forest is distinguished by its high values of soil moisture, due to the soil texture and to the soil flooding during the monsoon season. Beside these differences in soil moisture dynamics along the N-S gradient and for different surface types, all the soil moisture stations of the Gourma network show a 2005-2006 inter-annual variability which is characterised by a later monsoon in 2006. This is in agreement with atmospheric observations described in Janicot et al. (2008).

A case study is investigated, based on Bangui Mallam measurements, to address the vertical structure of soil moisture dynamics on coarse textured soils (Figure 3). Soil water budgets are computed for soil boxes between 0-1m and 1-2m, and compared to precipitation input for a 6-day period between July 28 and August 22006 (DoY 209-214). Fast soil water infiltration is depicted for the first meter of soil. After the $61.5 \mathrm{~mm}$ precipitation event that occurred on DoY 210, the wetting front is shown to reach $80 \mathrm{~cm}$ depth 1.5 days after the rain. The $1-2 \mathrm{~m}$ soil water content significantly increased about 2.75 day after a strong precipitation event occurred, whereas the 0-1m soil moisture budget already decreased. While the first meter of soil is characterised by very fast response of soil moisture to the atmospheric forcing, deeper soil is shown to respond at the seasonal time scale to atmospheric forcing and resulting land surface processes (infiltration and water uptake).

An up-scaling analysis of surface soil moisture is conducted in this paper, based on kilometer scale transect measurements performed in 2005 and 2006 on different coarse textured sites of the meso-scale area (section 4). An up-scaling relationship is determined and shown to be highly suitable to extrapolate kilometer scale surface soil moisture on the Bangui Mallam site for 2006 (equation 1). The accuracy is shown to be $1.6 \%$, with a 0.89 correlation with transect measurements. The high 
number of transect measurements performed at the Agoufou local site in 2005 and 2006 allows showing the inter-annual stability of the up-scaling relation for this site. Accordingly, equation 2 extrapolates surface soil moisture at the scale of $1 \mathrm{~km}$ from the Agoufou top of hillslope station, with an accuracy better than $1 \%$ in volumetric soil moisture. Based on the 2006 data set, the Agoufou top of hillslope station is shown to be the most representative station to derive the kilometer scale surface soil moisture at the Agoufou site.

This paper shows that the relationship between surface soil moisture and its $1 \mathrm{~km}$ spatial variability is very stable among the different sites of the Gourma meso-scale for the two studied years. Due to this consistency among the sites, the use of an unique multi-site up-scaling relation is shown to be accurate within $2.2 \%$ (volumetric) to retrieve $1 \mathrm{~km}$ scale surface soil moisture from station measurements.

This paper introduces measurements performed along an hydrological transect where elevation measurements were also performed. Discrete Fourier Transform of surface soil moisture and soil elevation show that significant variations of surface soil moisture are dominated by spatial periods of $250 \mathrm{~m}$ and $100 \mathrm{~m}$. Same dominant periods are shown for the soil elevation, which indicates that the soil moisture spatial variability is related to the soil topography along the transect. Soil moisture variations at scales smaller than $80 \mathrm{~m}$ are of lower amplitude and less related to topography. More investigations are however required to address the relative role of land surface cover, soil texture class and precipitation variability on the small scale soil moisture variability.

Surface soil moisture scaling is investigated further in section 5, where the Mean Relative Difference approach is applied to the Gourma super site. The Agoufou top of hillslope station is shown to be the most representative of the surface soil moisture variability (lowest standard deviation of the MRD) at the super site scale. Consistency of the results at different scales, from local to kilometer and from local to super sites scale, and with different approaches (transects and MRD), indicates 
that up-scaling features of surface soil moisture are consistent at the three considered spatial scales (local, $1 \mathrm{~km}$, super site). Based on these preliminary results, additional measurements are required to address the relation between local, transect and super site measurements. Measurements along a $50 \mathrm{~km}$ transect were performed in 2006 and 2007 (not shown here) and will be addressed in further studies.

The robustness of the surface soil moisture up-scaling relation for different coarse textured sites indicates that the Gourma meso scale soil moisture network is highly suitable for remote sensing and land surface modelling applications for which soil moisture is also required at larger scale than the station measurement. With the Bénin and Niger soil moisture networks, the Gourma soil moisture network has been selected to be a validation site for the future SMOS (Soil Moisture and Ocean Salinity Mission) (Kerr et al. 2001). Coordinated measurements of soil moisture, meteorological and flux measurements as well as vegetation measurements over the meso-scale site, makes the Gourma meso-scale soil moisture network of high interest in many research areas related to land surface processes and land-surfaceatmosphere interaction studies.

Acknowledgements. This research was funded by the API (Action Programmée Inter-organisme) in the framework of the AMMA-CATCH ORE (Couplage de l'Atmosphère Tropicale et du Cycle Hydrologique - Observatoire de Recherche sur l'Environnement) Program initiated by the French Ministry of Research. The authors thank Anton Beljaars and two anonymous reviewers for their useful comments on the manuscript.

\section{References}

[Baup et al. 2007] Baup, F., E. Mougin, P. de Rosnay, F. Timouk, and I. Chênerie, 2007: Surface soil moisture estimation over the AMMA Sahelian site in Mali using ENVISAT/ASAR data. Remote sens. environ., 109(4),473-481. 
[Boone et al. 2008] Boone, A., P. de Rosnay, G. Balsamo, A. Beljaars, F. Chopin, B. Decharme, C. Delire, A. Ducharne, S. Gascoin, F. Guichard, Y. Gusev, P. Harris, L. Jarlan, L. Kergoat, E. Mougin, O. Nasonova, A. Norgaard, T. d'Orgeval, C. Ottlé, I. Poccard-Leclercq, J. Polcher, I. Sandholt, S. Saux-Picart, C.M. Taylor, and X. Xue, 2008: The AMMA Land Surface Intercomparison Project (ALMIP), Bull. Amer. Meteorol. Soc, submitted.

[Bosch et al. 2006] Bosch, D.D., V. Lakshmi, T.J. Jackson, M. Choi, and J.M. Jacobs, 2006: Large scale measurements of soil moisture for validation of remotely sensed data: Georgia soil moisture experiment of 2003 Journal of Hydrology, 123.doi:10.1016/j.jhydrol.2005.08.024.

[Calvet et al. 1996] Calvet, J.-C., A. Chanzy, and J.-P. Wigneron, 1996: Surface temperature and soil moisture retrieval in the Sahel from airborne multifrequency microwave radiometry Geoscience and Remote Sensing, IEEE Transactions on IEEE Trans. Geosc. Remote Sens., 34 (2), pp 588-600.

[Chanzy et al. 1997] Chanzy, A., T.J. Schmugge, J.-C. Calvet, Y. Kerr, P. van Oevelen, O. Grosjean, and J.R. Wang, 1997: Airborne microwave radiometry on a semi-arid area during HAPEX-Sahel Journal of Hydrology, HAPEXSAHEL special issue, 188-189. pp 285-309

[Cosh et al. 2004] Cosh, M. H., T. J. Jackson, R. Bindlish, and J. H. Prueger, 2004: Watershed scale temporal and spatial stability of soil moisture and its role in validating satellite estimates. Remote sens. environ., 92, pp 427-435.

[De Lannoy et al. 2007] De Lannoy, G.J.M., P. Houser, and N. Verhoest, and V. Pauwels, and T Gish, 2007: Upscaling of point soil moisture observations to field averages at the OPE3 site. Journal of Hydrology, 343(1-2),pp 1-11, doi:10.1016/j.jhydrol.2007.06.004.

[Famiglietti et al. 1999] Famiglietti, J., J. Devereaux, C. Laymon, T. Tsegaye, P. Houser, T. Jackson, S. Graham, M. Rodell, and P. van Oevelen, 1999: Groundbased investigation of soil moisture variability within remote sensing footprints 
during the Southern Great Plains 1997 (SGP97) hydrology experiment. Water Resour. Res., 35(6), pp 1839-1851.

[Frappart et al. 2009] Frappart, F., P., Hiernaux, F., Guichard, E., Mougin, L., Kergoat, M., Arjounin, F., Lavenu, M., Koité, J.-E., Paturel, T., and Lebel, 2009: Rainfall regime over the Sahelian climate gradient in the Gourma, Mali. Journal of Hydrology, this issue.

[Gee and Bauder 1986] Gee, G., and J. Bauder, 1986: Particule size analysis. A. Klute (Ed.) Method of size analysis. Parti I, 2nd ed., Agronomy Monograph.9, American Society of Agronomy, Madison, WI, 4,383-411.

[Greminger et al. 1985] Greminger, P.J., Y.K. Sud, and D.R. Nielsen, 1985: Spatial variability of field-measured soil-water characteristics, Soil Sci. Soc. Am. J., 49(5), 1075-1082.

[Gruhier et al. 2008] Gruhier, C., P. de Rosnay, Y. Kerr, E. Mougin, E. Ceschia, C. J.-C., and P. Richaume, 2008: Evaluation of AMSR-E Soil Moisture Products Based on Ground Soil Moisture Network Measurements. Geophy. Res. Letters, 35, L10405, doi:10.1029/2008GL033330.

[Hiernaux et al. 2009] Hiernaux, P., E. Mougin, L. Diarra, N. Soumaguel, F. Lavenu, Y. Tracol, and M. Diawara, 2009: Sahelian rangeland response to changes in rainfall over two decades in the Gourma region, Mali. Journal of Hydrology, this issue.

[Janicot et al. 2008] Janicot, S., A. Ali, A. Asencio, G. Berry, O. Bock, B. Bourles, G. Ganiaux, F. Chauvin, A. Deme, L. Kergoat, J.-P. Lafore, C. Lavaysse, T. Lebel, B. Marticorena, F. Mounier, J.-L. Redelsperger, C. Reeves, R. Roca, P. de Rosnay, B. Sultan, C. Thorncroft, M. Tomasini, and A. forcasters team, 2008: Large scale overview of the summer monsoon over West and Central Africa during AMMA field experiment in 2006. Ann. Geophys., 26(9), pp2569-2595.

[Jackson et al. 2003] Jackson, T., R. Bindlish, M. Klein, A.J. Gasiewski, and E. Njoku, 2003: Soil moisture retrieval and AMSR-E validation using an airborne 
microwave radiometer in SMEX02, Proceedings of IEEE International Geoscience and Remote Sensing Symposium 2003, IGARSS'03., Vol.1, pp.401-403.

[Jackson et al. 1997] Jackson, T., P. O'Neill and C.T. Swift, 1997: Passive microwave observation of diurnal surface moil moisture, IEEE Trans. Geosc. Remote Sens., 35, pp. 1210-1222.

[Jarlan et al. 2008] Jarlan, L., G. Balsamo, S. Lafont, A. Beljaars, J.-C. Calvet, and E. Mougin, 2008: Analysis of leaf area index in the ecmwf land surface scheme and impact on latent heat and carbon fluxes: Application to west africa. J. Geophys. Res., in press.

[Kerr 2007] Kerr, Y. H., 2007: Soil Moisture from space: Where we are ? Hydrogeology journal, 15,117-120.

[Kerr et al. 2001] Kerr, Y. H., P. Waldteufel, J.-P. Wigneron, J.-M. Martinuzzi, J. Font, and M. Berger, 2001: Soil moisture retrieval from space: the soil moisture and ocean salinity (SMOS) mission. IEEE Trans. Geosc. Remote Sens., 39 (8),1729-1735.

[Kim and Barros 2002] Kim, G., and A. Barros, 2002: Space-time characterization of soil moisture from passive microwave remotely sensed imagery and ancillary data. Remote sens. environ., 81, 393-403.

[Koster et al. 2004] Koster, R. D., P. Dirmeyer, Z. Guo, G. Bonan, P. Cox, C. Gordon, S. Kanae, E. Kowalczyk, D. Lawrence, P. Liu, C. Lu, S. Malyshev, B. McAvaney, K. Mitchell, D. Mocko, T. Oki, K. Oleson, A. Pitman, Y. Sud, C. Taylor, D. Verseghy, R. Vasic, Y. Xue, and T. Yamada, 2004: Regions of strong coupling between soil moisture and precipitation. Sciences, 305, pp1138-1140.

[Le Dantec et al. 2006] Le Dantec, V., J. Seghieri, E. Mougin, P. Hiernaux, F. Timouk, V. Demarez, L. Kergoat, F. Lavenu, P. de Rosnay, M.-N. Mulhaupt, N. Soumagel, A. Moctar, C. Damesin, J. Bennie, L. Mercado, D. Epron, R. Dupont, and S. D., 2006: Carbon and Water Exchanges at the Gourma site (Mali). SOP Debriefing and Preparation of Process Studies, Toulouse, France. 
[Lebel and Ali 2009] Lebel, T., and A. Ali, 2009: Recent trends in the Central Sahel rainfall regime (1990 - 2007). Journal of Hydrology, this issue.

[Le Morvan et al. 2008] Le Morvan, A., M. Zribi, N. Baghdadi, A. Chanzy, 2008: Soil Moisture Profile Effect on Radar Signal Measurement. Sensors. 8, pp 256270.

[Lloyd 1997] Lloyd, C.R., P. Bessemoulin, F.D. Cropley, A.D. Culf, A.J. Dolman, J. Elbers, B. Heusinkveld, J.B. Moncrieff, B. Monteny, and A. Verhoef, 1997: A comparison of surface fluxes at the HAPEX-Sahel fallow bush sites. Journal of Hydrology, HAPEX-SAHEL special issue, 188-189 pp 400-425.

[Magagi and Kerr 1997] Magagi, R. and Y.H Kerr, 1997: Retrieval of soil moisture and vegetation characteristics by use of ERS-1 wind scatterometer over arid and semi-arid areas Journal of Hydrology, HAPEX-SAHEL special issue, 188-189, pp 361-384, doi:10.1016/S0022-1694(96)03166-6 .

[Monteny et al. 1997] Monteny, B.A., J.-P. Lhomme, A. Chehbouni, D. Troufleau, M. Amadou, M. Sicot, A. Verhoef, S. Galle, F. Said, and C.R. Lloyd 1997: The role of the Sahelian biosphere on the water and the CO2 cycle during the HAPEXSahel experiment Journal of Hydrology, HAPEX-SAHEL special issue, 188-189, pp 516-535, doi:10.1016/S0022-1694(96)03191-5.

[1] Mougin, E., P. Hiernaux, L. Kergoat, M. Grippa, P. de Rosnay, F. Timouk, V. Le Dantec, V. Demarez, M. Ajournin, F. Lavenu, N. Soumaguel, E. Ceschia, B. Mougenot, F. Baup, F. Frappart, P.-L. Frison, J. Gardelle, C. Gruhier, L. Jarlan, S. Mangiarotti, B. Sanou, Y. Tracol, F. Guichard, V. Trichon, L. Diarra, A. Soumaré, M. Koité, F. Dembélé, C. Lloyd, N. P. Hanan, C. Damesin, C. Delon, D. Sercca, C. Galy-Lacaux, J.Seghiéri, S. Becerra, H. Dia, F. Gangneron, P. Mazzega, 2009: The AMMA-CATCH Gourma observatory site in Mali: Relating climatic variations to changes in vegetation, surface hydrology, fluxes and natural resources. Journal of Hydrology, this issue.

[Nicholson et al. 1997] Nicholson, S.E., J A. Marengo, J. Kim, A.R. Lare, S. Galle 
and Y.H. Kerr, 1997: A daily resolution evapoclimatonomy model applied to surface water balance calculations at the HAPEX-Sahel supersites Journal of Hydrology, HAPEX-SAHEL special issue, 188-189, doi:10.1016/S0022-1694(96)03178-2 , pp 946-964 .

[Redelsperger et al. 2006] Redelsperger, J.-L., C., Thorncroft, A., Diedhiou, T., Lebel, D., Parker, and J., Polcher, 2006: African Monsoon, Multidisciplinary Analysis (AMMA): An International Research Project and Field Campaign. Bull. Amer. Meteorol. Soc, 87(12), pp 1739-1746.

[Rüdiger et al. 2007] Rüdiger, C., G. Hancock, M.H. Hemakumara, B. Jacobs, J. Kalma, C. Martinez, M. Thyer, J.P. Walker, T. Wells, and G.R. Willgoose, 2007: Goulburn River experimental catchment data set. Water Resources Research, 43, W10403, doi:10.1029/2006WR005837.

[Seghieri et al. 2009] Seghieri, J., A. Vescovo, K. Padel, R. Soubié, M. Arjounin, N. Boulain, P. de Rosnay, S. Galle, M. Gosset, A. Mouctar, C. Peugeot, F. Timouk, 2009: Relationships between climate, soil moisture and phenology of the woody cover in two sites located along the West African latitudinal gradient. Journal of Hydrology, this issue.

[Schmugge 1998] Schmugge, T., 1998: Applications of passive microwave observations of surface soil moisture. Journal of Hydrology, 212-213 pp 188-197.

[Taylor and Ellis 2006] Taylor, C., R. Ellis 2006: Satellite detection of soil moisture impacts on convection at the mesoscale, Geophy. Res. Letters, 33, L03404,doi:10.1029/2007GL030572.

[Taylor et al. 2007] Taylor, C., L. Kergoat, and P. de Rosnay 2007: Land Surface Atmosphere Interactions During the AMMA SOP CLIVAR Exchanges News Letter, 12, 2, N 41 April 2007.

[Timouk et al. 2009] Timouk, F., L. Kergoat, E. Mougin, C. Lloyd, E. Ceschia, P. de Rosnay, P. Hiernaux, V. Demarez, and C. Taylor, 2009: The Response of sensible heat flux to water regime and vegetation development in a central 
794 Sahelian landscape. Journal of Hydrology, this issue.

795 [Vachaud et al. 1985] Vachaud, G., A. Passerat De Silans, P. Balabanis, and 796 M. Vauclin, 1985: Temporal Stability of Spatially Measured Soil Water Prob797 ability Density Function. Soil Sci. Soc. Am. J., 49, 822-828.

798 [Zribi et al. 2009] Zribi, M., M. Pardé, P. de Rosnay, F. Baup, L. Descroix, C. Ottlé, 799 and B. Decharme, 2009: ERS Scatterometer surface soil moisture analysis of two 800 sites in the south and north of the Sahel region of West Africa. Journal of 801 Hydrology, this issue. 


\section{List of Figures}

1 Location of the 10 automatic soil moisture stations (white stars), for the Gourma meso-scale site (left) and for the super-site (right).

2 Volumetric surface (5cm) soil moisture (in \%), evolution for 2005 and 2006 for eight different sites located along the North-South gradient of the Gourma region of Mali.

3 Top panel: temporal dynamics of volumetric soil moisture at different soil depths at Bangui Mallam in 2006. Middle panel shows the vertical profiles of volumetric soil moisture at different dates, before rain (DoY 209, July 28), after a major rainfall event (DoY 210), and after two additional rainfall events (DoY 214, August 2). Bottom panel depicts, for DoY 202 to DoY 214, the temporal evolution of the accumulated precipitation (black line), vertically integrated soil water content on the $0-1 \mathrm{~m}$ soil layer (dotted line) and on the 1-2m soil layer (dashed line).

4 Transect measurements of surface soil moisture at three different dates in August 2006. For each date, the mean value of surface soil moisture (SM) and its standard deviation (STD) are indicated.

5 Surface soil moisture estimated at the $1 \mathrm{~km}$ scale from transect measurements (vertical axis) and from the local Agoufou top of hillslope station measurements to which was applied the equation 2 up-scaling relation (horizontal axis).

6 Multi-site transect measurements. On the left panel, surface soil moisture estimated at the $1 \mathrm{~km}$ scale from transect measurements on different coarse textured sites (vertical axis) and from the nearest stations measurements to which was applied the multi-site up-scaling relation equation 4 (horizontal axis). On the right panel, relation between transects surface soil moisture spatial variability and the averaged surface soil moisture values.

$7 \quad$ Surface soil moisture (top panel) and topography (bottom panel) along the hydrological transect. Four transects are shown here for different soil moisture conditions. Very wet conditions are shown on 19 August since a heavy rainfall event occurred a few hour before, on the $18^{\text {th }}$ August in the evening. 13 and 15 August are respectively 4 and 6 days after the rainfall event of the 9 August. 
8 Amplitude of the Discrete Fourier Transform of the topography (thick black line) and the surface soil moisture at 3 different dates (thin lines) for different soil moisture conditions indicated in Figure 7. The abscissa axe is the spatial period in meter. The amplitude is expressed in $m$ and in $m^{3} m^{-3}$ for the elevation and soil moisture respectively.

9 Mean Relative Difference (MRD) and its time Standard Deviation (STD) (see text, section 5) for the volumetric surface soil moisture of each of the five stations considered at the Agoufou super site scale compared to the site average. 


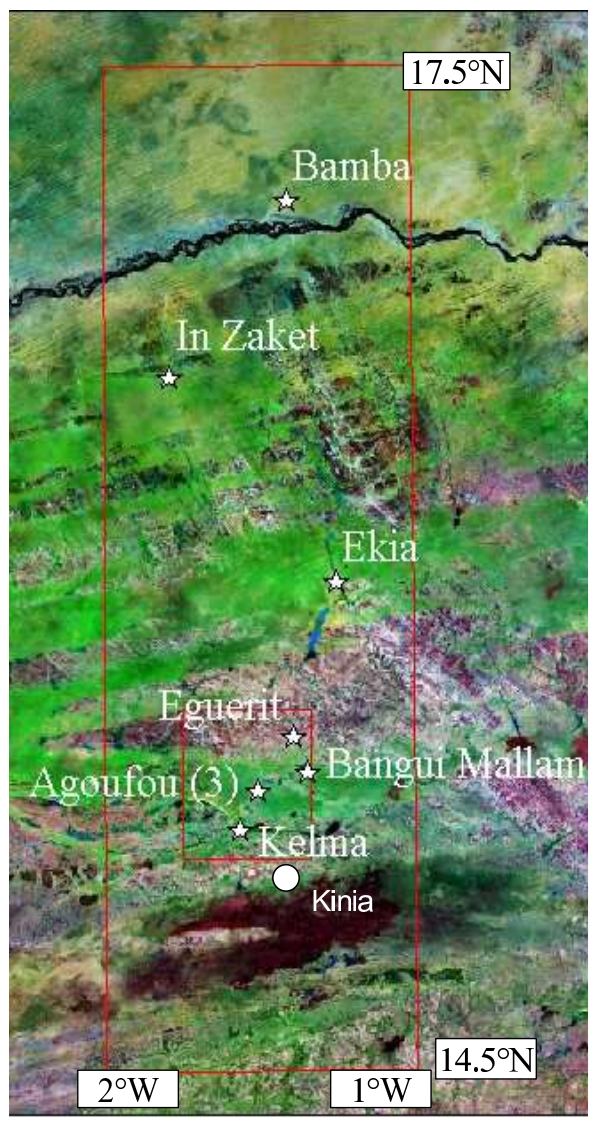

Gourma meso-scale site

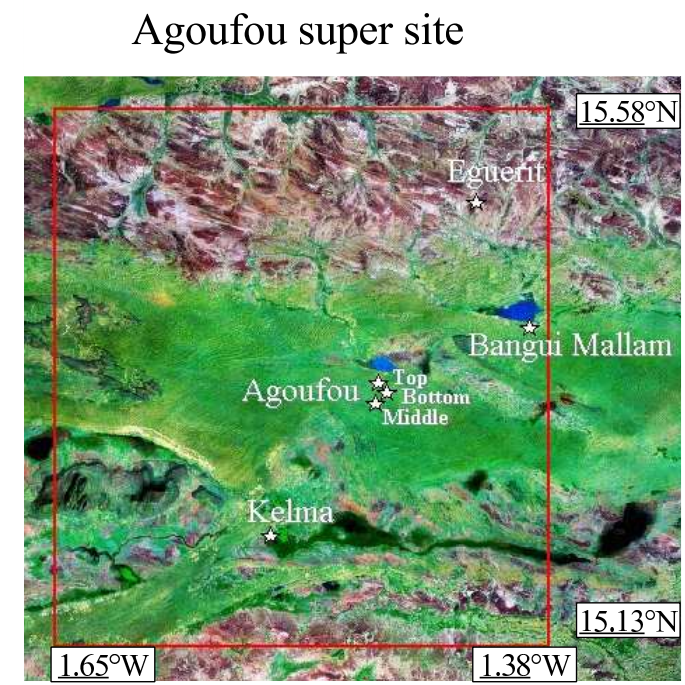

Fig. 1. Location of the 10 automatic soil moisture stations (white stars), for the Gourma meso-scale site (left) and for the super-site (right). 

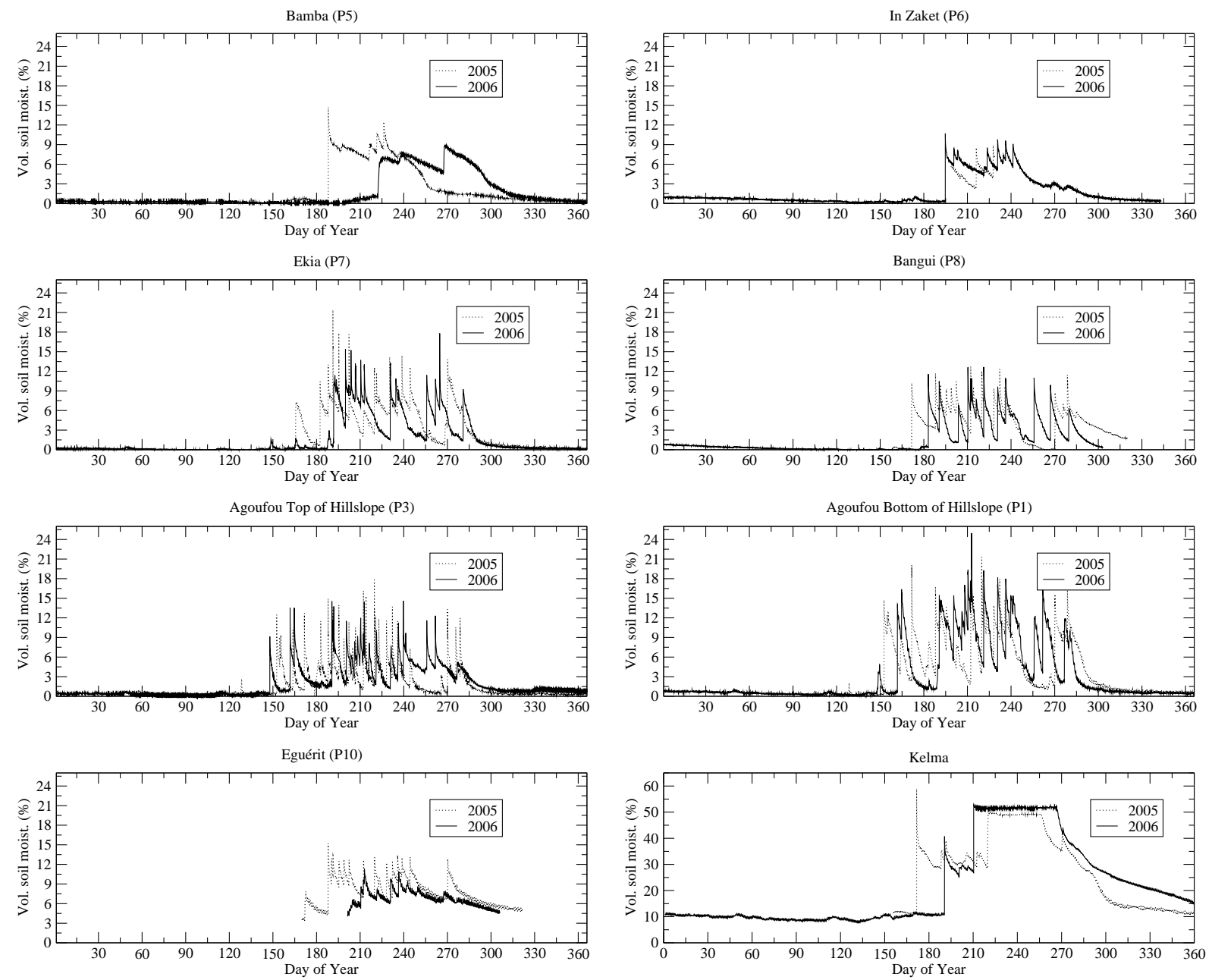

Fig. 2. Volumetric surface (5cm) soil moisture (in \%), evolution for 2005 and 2006 for eight different sites located along the North-South gradient of the Gourma region of Mali. 

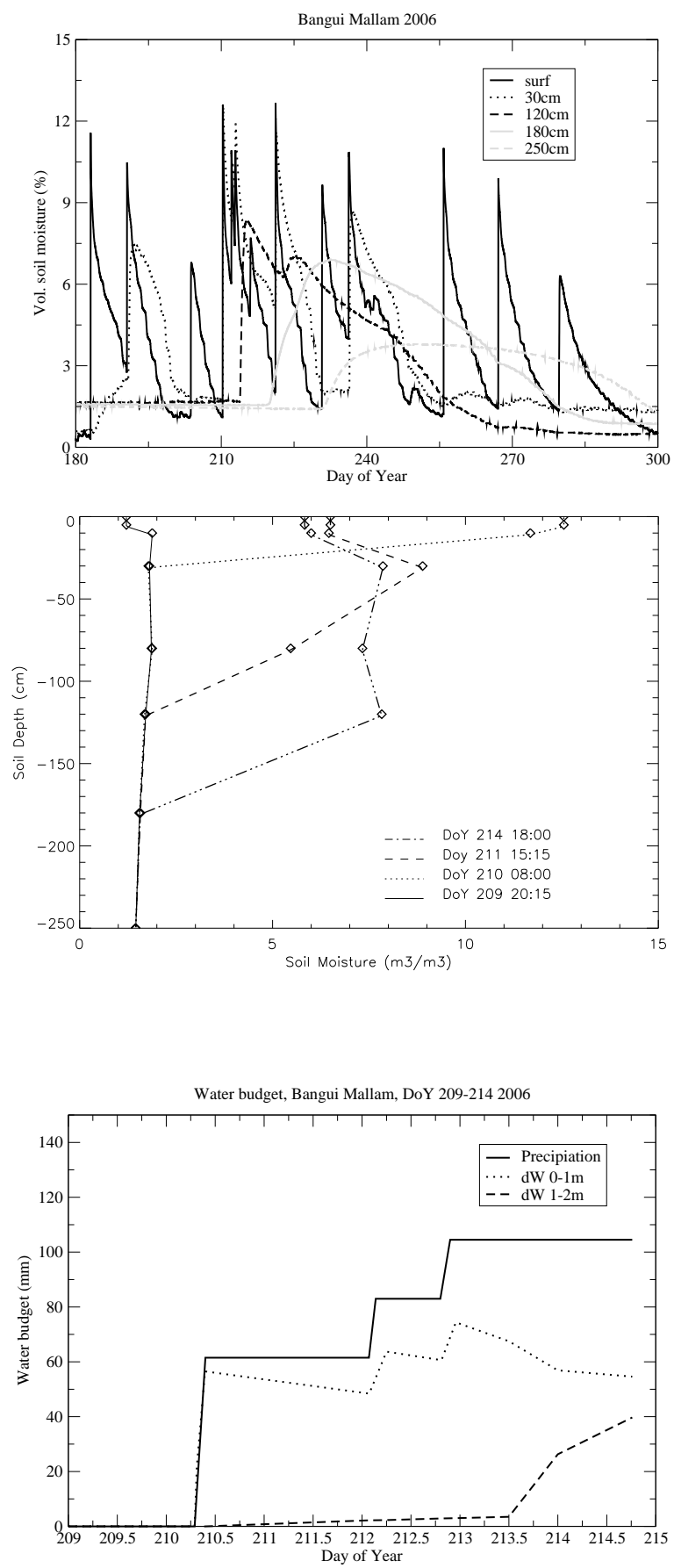

Fig. 3. Top panel: temporal dynamics of volumetric soil moisture at different soil depths at Bangui Mallam in 2006. Middle panel shows the vertical profiles of volumetric soil moisture at different dates, before rain (DoY 209, July 28), after a major rainfall event (DoY 210), and after two additional rainfall events (DoY 214, August 2). Bottom panel depicts, for DoY 202 to DoY 214, the temporal evolution of the accumulated precipitation (black line), vertically integrated soil water content on the $0-1 \mathrm{~m}$ soil layer (dotted line) and on the $1-2 \mathrm{~m}$ soil layer (dashed line). 


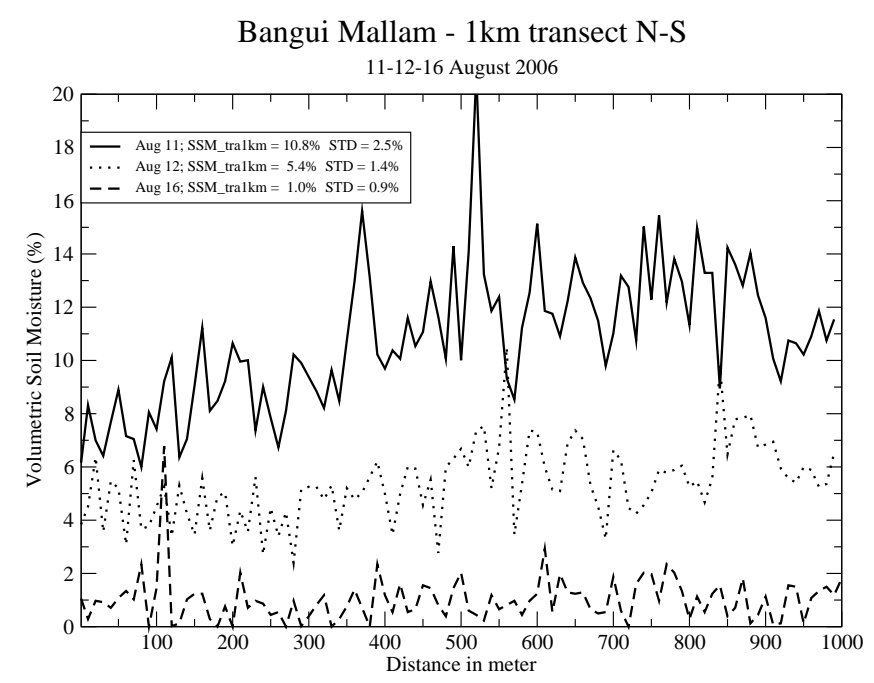

Fig. 4. Transect measurements of surface soil moisture at three different dates in August 2006. For each date, the mean value of surface soil moisture (SM) and its standard deviation (STD) are indicated. 


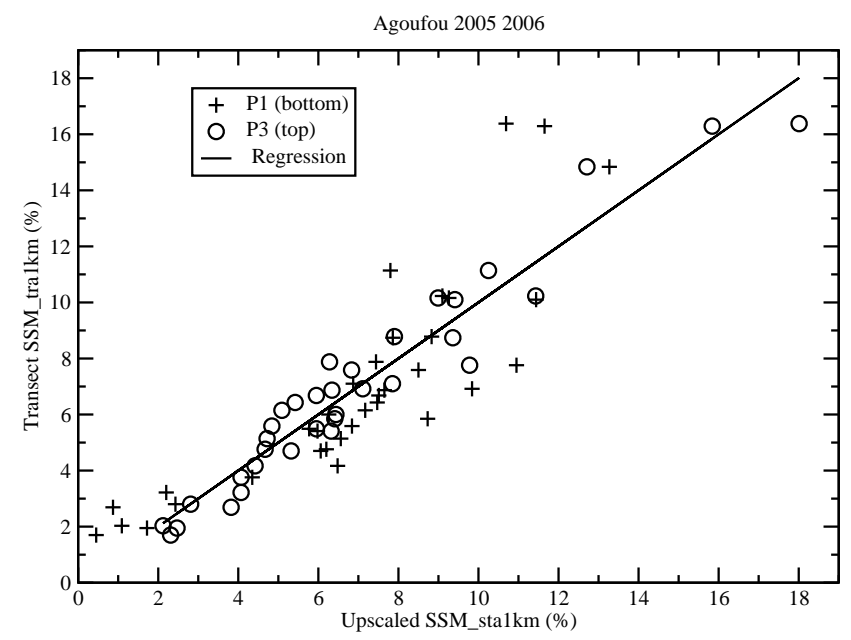

Fig. 5. Surface soil moisture estimated at the $1 \mathrm{~km}$ scale from transect measurements (vertical axis) and from the local Agoufou top of hillslope station measurements to which was applied the equation 2 up-scaling relation (horizontal axis). 

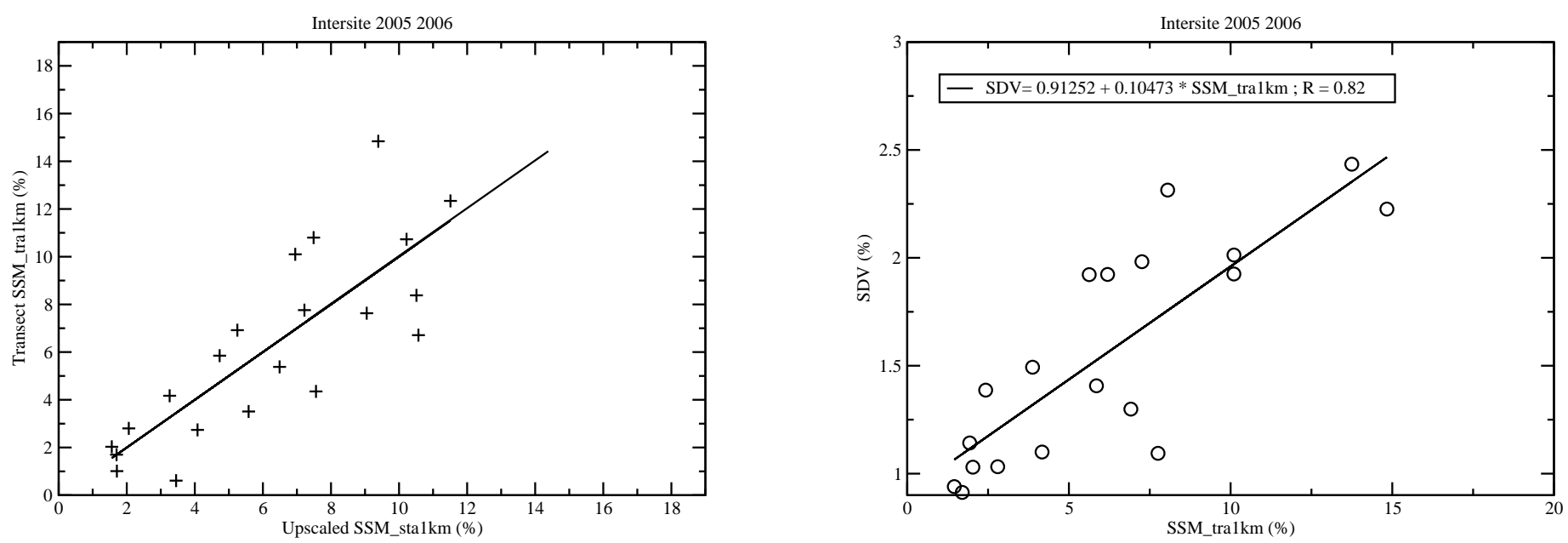

Fig. 6. Multi-site transect measurements. On the left panel, surface soil moisture estimated at the $1 \mathrm{~km}$ scale from transect measurements on different coarse textured sites (vertical axis) and from the nearest stations measurements to which was applied the multi-site up-scaling relation equation 4 (horizontal axis). On the right panel, relation between transects surface soil moisture spatial variability and the averaged surface soil moisture values. 
SITE 17 - hydrological transect
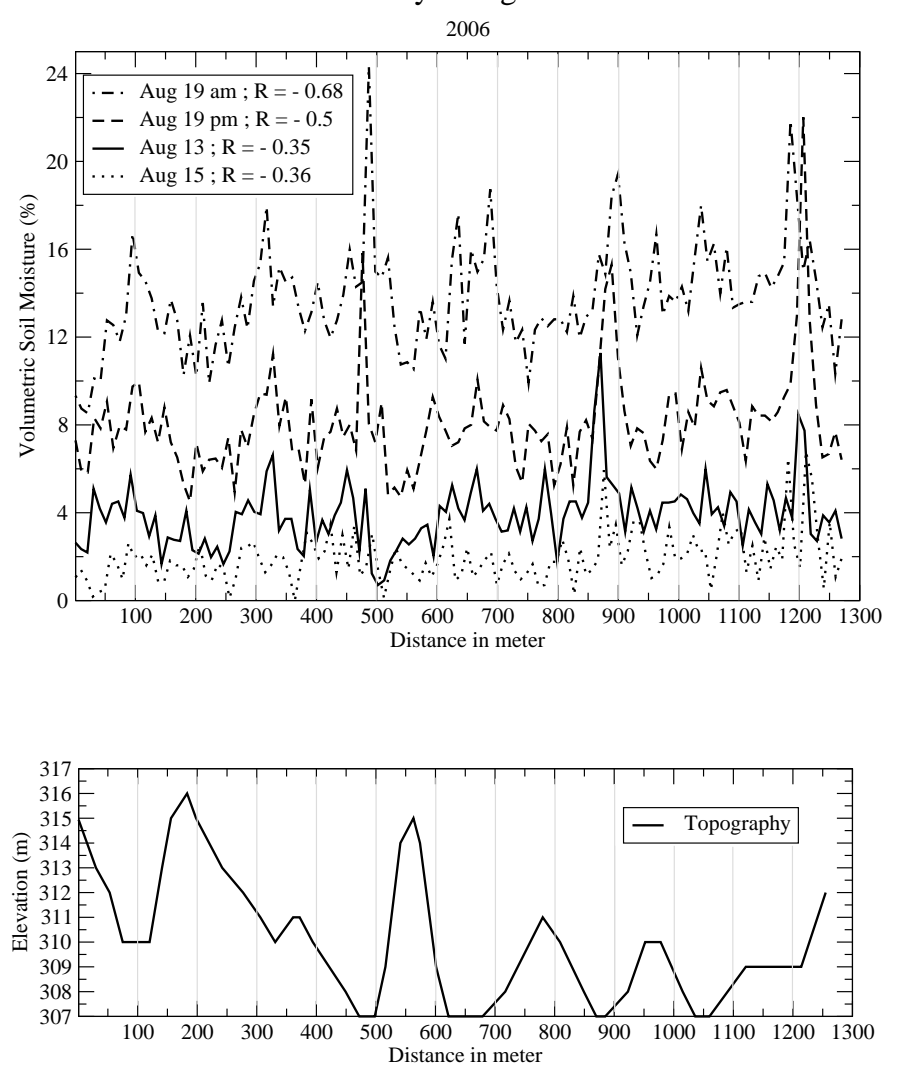

Fig. 7. Surface soil moisture (top panel) and topography (bottom panel) along the hydrological transect. Four transects are shown here for different soil moisture conditions. Very wet conditions are shown on 19 August since a heavy rainfall event occurred a few hour before, on the $18^{\text {th }}$ August in the evening. 13 and 15 August are respectively 4 and 6 days after the rainfall event of the 9 August. 


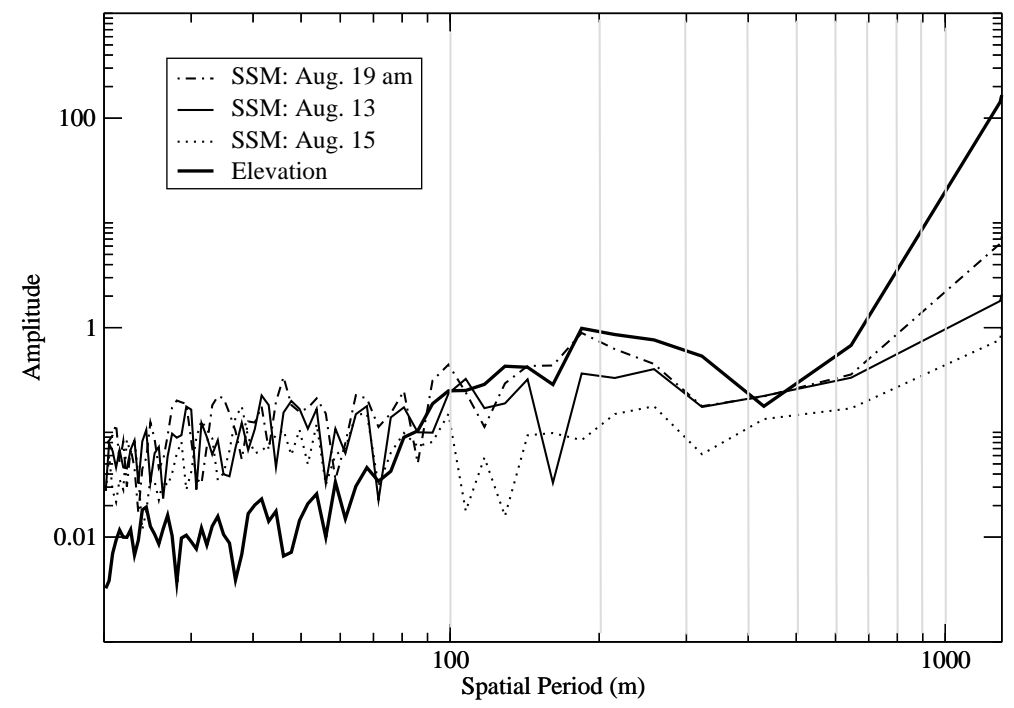

Fig. 8. Amplitude of the Discrete Fourier Transform of the topography (thick black line) and the surface soil moisture at 3 different dates (thin lines) for different soil moisture conditions indicated in Figure 7 . The abscissa axe is the spatial period in meter. The amplitude is expressed in $m$ and in $m^{3} m^{-3}$ for the elevation and soil moisture respectively. 


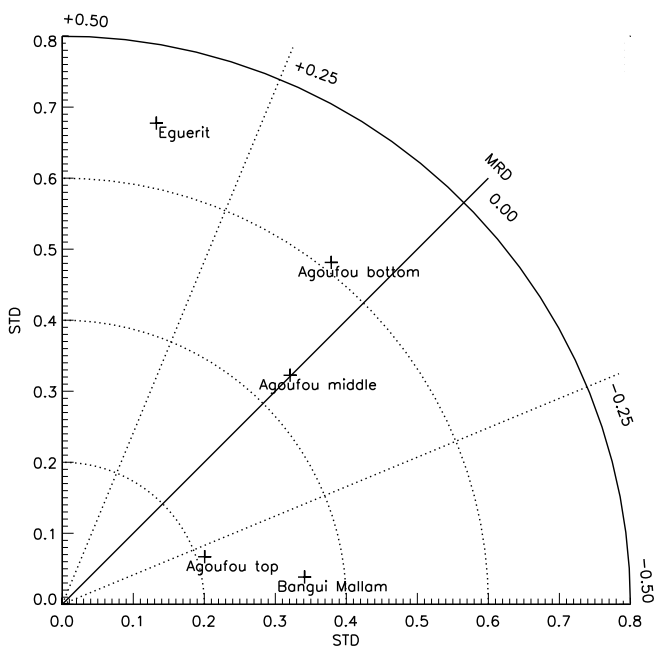

Fig. 9. Mean Relative Difference (MRD) and its time Standard Deviation (STD) (see text, section 5) for the volumetric surface soil moisture of each of the five stations considered at the Agoufou super site scale compared to the site average. 
1 Soil Moisture stations installed at the Gourma meso-scale site. Name and location of each stations are indicated, as well as the depth of measurements and date of installation. Qualitative indication of surface soil texture is indicated for each station, expect for Eguérit which has rocky soil. US Department of Agriculture (USDA) soil texture is given for Agoufou top and bottom of hillslope, where texture measurements were performed (Table 2).

2 Vertical profile of soil texture on the Agoufou local site. Fraction are indicated in per thousand. Particles size are defined according to the USDA classification scheme, with clay $(<0.002 \mathrm{~mm})$, fine silt $(0.002-0.02 \mathrm{~mm})$, coarse silt $(0.02-0.05 \mathrm{~mm})$, fine sand $(0.05-0.2 \mathrm{~mm})$, coarse sand $(0.2-2 \mathrm{~mm})$ (Gee and Bauder 1986).

3 Number of transect measurements performed in 2005 and 2006 on Agoufou and some of the others coarse textured sites.

4 Statistical results of the comparison between the kilometer scale surface soil moisture obtained by up-scaling of local station measurements, $S S M_{s t a 1 k m}$, and transect measurements, $S S M_{\text {tra1km }}$ (see text). For each row a data set is selected corresponding to different sites and different years. The number of observations is indicated by $N$ in the last column. 
Site

Location

Sensors types and depth $(\mathrm{cm})$

date

\begin{tabular}{|c|c|c|c|c|c|c|c|}
\hline Number & Name & Soil Text. & Lat. & Lon. & Soil Moisture & Temperature & \\
\hline $17-\mathrm{P} 1$ & $\begin{array}{l}\text { Agoufou } \\
\text { bottom }\end{array}$ & Sandy-Loam & $15.341^{\circ} \mathrm{N}$ & $1.479^{\circ} \mathrm{W}$ & $\begin{array}{l}7 \mathrm{CS} 616 \\
5,30,60,120,150,250,400\end{array}$ & $\begin{array}{l}4 \mathrm{PT} 108 \\
5,30,60,120\end{array}$ & 04-2005 \\
\hline $17-\mathrm{P} 2$ & middle & Coarse & $15.345^{\circ} \mathrm{N}$ & $1.479^{\circ} \mathrm{W}$ & $6 \mathrm{CS} 616$ & 2 PT108 & 04-2006 \\
\hline $17-\mathrm{P} 3$ & top & Sand & $15.345^{\circ} \mathrm{N}$ & $1.479^{\circ} \mathrm{W}$ & $\begin{array}{l}5,30,60,120,180,250 \\
5 \text { CS616 } \\
5,10,40,120,220\end{array}$ & $\begin{array}{l}5,30 \\
2 \text { PT108 } \\
5,40\end{array}$ & 04-2004 \\
\hline $\mathrm{BB}-\mathrm{P} 5$ & Bamba & Coarse & $17.099^{\circ} \mathrm{N}$ & $1.402^{\circ} \mathrm{W}$ & $\begin{array}{l}6 \mathrm{CS} 616 \\
5,40,80,120,180,250\end{array}$ & $\begin{array}{l}5 \mathrm{PT} 108 \\
5,10,40,80,120\end{array}$ & 04-2004 \\
\hline $4-\mathrm{P} 6$ & In Zaket & Coarse & $16.572^{\circ} \mathrm{N}$ & $1.789^{\circ} \mathrm{W}$ & $\begin{array}{l}7 \text { CS616 } \\
5,10,30,80,120,180,250\end{array}$ & $\begin{array}{l}4 \mathrm{PT} 108 \\
5,10,30,80\end{array}$ & 07-2005 \\
\hline $12-\mathrm{P} 7$ & Ekia & Coarse & $15.965^{\circ} \mathrm{N}$ & $1.253^{\circ} \mathrm{W}$ & $\begin{array}{l}7 \text { CS616 } \\
5,10,30,80,120,180,250\end{array}$ & $\begin{array}{l}4 \mathrm{PT} 108 \\
5,10,30,80\end{array}$ & 06-2005 \\
\hline EM - P8 & $\begin{array}{l}\text { Bangui } \\
\text { Mallam }\end{array}$ & Coarse & $15.398^{\circ} \mathrm{N}$ & $1.345^{\circ} \mathrm{W}$ & $\begin{array}{l}7 \text { CS616 } \\
5,10,30,80,120,180,250\end{array}$ & $\begin{array}{l}4 \mathrm{PT} 108 \\
5,10,30,80\end{array}$ & 04-2005 \\
\hline $20-\mathrm{P} 9$ & Kelma & Fine & $15.218^{\circ} \mathrm{N}$ & $1.566^{\circ} \mathrm{W}$ & $\begin{array}{l}4 \text { Theta-probes } \\
5,20,80,100\end{array}$ & $\begin{array}{l}4 \text { PT108 } \\
5,20,80,100 \\
\end{array}$ & 06-2005 \\
\hline $40-\mathrm{P} 10$ & Eguérit & Rock & $15.503^{\circ} \mathrm{N}$ & $1.392^{\circ} \mathrm{W}$ & $\begin{array}{l}2 \mathrm{CS} 616 \\
10,50\end{array}$ & $\begin{array}{l}4 \text { PT108 } \\
10,50\end{array}$ & 04-2005 \\
\hline $25-\mathrm{P} 11$ & Kinia & Coarse & $15.051^{\circ} \mathrm{N}$ & $1.546^{\circ} \mathrm{W}$ & $\begin{array}{l}7 \mathrm{CS} 616 \\
5,10,30,80,120,180,250\end{array}$ & $\begin{array}{l}4 \mathrm{PT} 108 \\
5,10,30,80\end{array}$ & 03-2007 \\
\hline
\end{tabular}

Table 1

Soil Moisture stations installed at the Gourma meso-scale site. Name and location of each stations are indicated, as well as the depth of measurements and date of installation. Qualitative indication of surface soil texture is indicated for each station, expect for Eguérit which has rocky soil. US Department of Agriculture (USDA) soil texture is given for Agoufou top and bottom of hillslope, where texture measurements were performed (Table 2). 


\begin{tabular}{|c|c|c|c|c|c|}
\hline \multicolumn{6}{|c|}{ Bottom of hillslope } \\
\hline Depth (cm) & Clay & Fine Silt & Coarse Silt & Fine Sand & Coarse Sand \\
\hline 5 & 96 & 89 & 69 & 352 & 394 \\
\hline 10 & 53 & 31 & 28 & 338 & 550 \\
\hline 20 & 68 & 31 & 18 & 348 & 535 \\
\hline 30 & 78 & 32 & 15 & 355 & 520 \\
\hline 40 & 87 & 31 & 19 & 392 & 471 \\
\hline 50 & 82 & 27 & 15 & 377 & 499 \\
\hline 60 & 90 & 26 & 26 & 438 & 420 \\
\hline 70 & 86 & 26 & 11 & 445 & 432 \\
\hline 80 & 90 & 22 & 12 & 505 & 371 \\
\hline 90 & 86 & 18 & 15 & 524 & 357 \\
\hline 100 & 78 & 13 & 19 & 544 & 346 \\
\hline \multicolumn{6}{|c|}{ Top of Hillslope } \\
\hline Depth $(\mathrm{cm})$ & Clay & Fine Silt & Coarse Silt & Fine Sand & Coarse Sand \\
\hline 5 & 34 & 11 & 13 & 385 & 557 \\
\hline 10 & 34 & 14 & 13 & 421 & 518 \\
\hline 20 & 37 & 18 & 6 & 418 & 521 \\
\hline 30 & 44 & 11 & 4 & 431 & 510 \\
\hline 40 & 47 & 8 & 1 & 507 & 437 \\
\hline 50 & 42 & 9 & 3 & 469 & 477 \\
\hline 60 & 40 & 6 & 8 & 448 & 498 \\
\hline 70 & 42 & 2 & 5 & 462 & 489 \\
\hline 80 & 36 & 4 & 4 & 465 & 491 \\
\hline 90 & 33 & 3 & 2 & 453 & 509 \\
\hline 100 & 29 & 11 & 8 & 533 & 419 \\
\hline
\end{tabular}

Vertical profile of soil texture on the Agoufou local site. Fraction are indicated in per thousand. Particles size are defined according to the USDA classification scheme, with clay $(<0.002 \mathrm{~mm})$, fine silt $(0.002-0.02 \mathrm{~mm})$, coarse silt $(0.02-0.05 \mathrm{~mm})$, fine sand (0.05-0.2mm), coarse sand (0.2-2mm) (Gee and Bauder 1986). 


\begin{tabular}{llll} 
Site & 2005 & 2006 & Direction \\
\hline Agoufou & 25 & 9 & West \\
Bangui Mallam & 1 & 7 & South \\
Bamba & 1 & 0 & North \\
Ekia & 1 & 2 & South \\
Agoufou-hydro & 0 & 10 & Topographical \\
\hline Total & 28 & 28 &
\end{tabular}

Table 3

Number of transect measurements performed in 2005 and 2006 on Agoufou and some of the others coarse textured sites. 


\begin{tabular}{ll|llll|l} 
Site & Year & $R M S E(\%)$ & $R$ & $\mathrm{EFF}$ & $\mathrm{BIAS}$ & $N$ \\
\hline Bangui Mallam & 2006 & 1.6 & 0.89 & 0.8 & $10^{-4}$ & 7 \\
\hline Agoufou & $2005-2006$ & & & & & \\
Top (P3) & & 0.9 & 0.97 & 0.94 & $10^{-4}$ & 34 \\
Bottom (P1) & & 1.9 & 0.86 & 0.73 & $10^{-4}$ & 34 \\
\hline Agoufou & 2006 & & & & & \\
Top (P3) & & 0.97 & 0.97 & 0.94 & $10^{-4}$ & 9 \\
Bottom (P1) & & 1.7 & 0.91 & 0.83 & $10^{-5}$ & 9 \\
Middle (P2) & & 1.4 & 0.94 & 0.88 & $10^{-4}$ & 9 \\
\hline Multi-site & $2005-2006$ & 2.2 & 0.82 & 0.66 & $10^{-4}$ & 21
\end{tabular}

Table 4

Statistical results of the comparison between the kilometer scale surface soil moisture obtained by up-scaling of local station measurements, $S S M_{s t a 1 \mathrm{~km}}$, and transect measurements, $S S M_{t r a 1 k m}$ (see text). For each row a data set is selected corresponding to different sites and different years. The number of observations is indicated by $N$ in the last column. 